\title{
Individual Differences in Students' Effort Source Beliefs Predict Their Judgments of Ability
}

\author{
David B. Miele, Alexander S. Browman, and Marina Vasilyeva
}

Boston College ${ }^{\mathrm{a}}$

a Department of Counseling, Developmental, and Educational Psychology, Boston College, 140 Commonwealth Avenue, Chestnut Hill, MA, 02467. Emails: d.miele@bc.edu, browman@bc.edu,marina.vasilyeva@bc.edu

Author Note

Correspondence concerning this article should be addressed to David B. Miele, Department of Counseling, Developmental, and Educational Psychology, Boston College, Chestnut Hill, MA 02467 (d.miele@bc.edu). Support for this research was provided by the Buehler Sesquicentennial Assistant Professorship and by Collaborative Grant No. 220020483 from the James S. McDonnell Foundation.

Supplementary Materials:

http://supp.apa.org/psycarticles/supplemental/mot0000124/mot0000124_supp.html

(C) American Psychological Association, 2019.

This paper is not the copy of record and may not exactly replicate the authoritative document published in the APA journal. Please do not copy or cite without author's permission. The final article is available, upon publication, at http://dx.doi.org/10.1037/mot0000124 


\begin{abstract}
A recent set of studies (Muenks, Miele, \& Wigfield, 2016) introduced the concept of perceived effort source to better explain how students reason about the relation between effort and ability when evaluating the academic abilities of other students. These studies showed that participants who were induced to perceive effort as task-elicited (i.e., as being primarily due to the subjective difficulty of the task) were more likely to view effort and ability as inversely related than participants who were induced to perceive effort as self-initiated (i.e., as being due to students' motivation to go beyond the basic demands of the task). The current studies expanded on this research by demonstrating that, in the absence of an effort source manipulation, college students spontaneously invoked beliefs about the source of effort when evaluating their own (Study 2) and other students' (Studies 1-3) abilities. The three studies also showed that our novel measure of individual differences in effort source beliefs was a better predictor of participants' judgments of math ability (Studies 1 and 2) and verbal ability (Study 3) than a standard measure of their ability mindsets (i.e., beliefs about the extent to which intelligence is malleable). Specifically, participants who naturally tended to perceive effort as task-elicited generally rated students who expended relatively little effort as having more ability than did participants who tended to perceive effort as self-initiated. Implications for research on student motivation and for education practice are discussed.
\end{abstract}

Keywords: perceived effort source; judgments of ability; mindsets; motivation 


\section{Individual Differences in Students' Effort Source Beliefs Predict Their Judgments of Ability}

Students' perceptions of their own and others' academic abilities are among the most important determinants of their academic engagement and motivation. With respect to selfjudgments of ability, highly influential theories of student motivation (such as expectancy-value theory and self-efficacy theory) and numerous supporting studies suggest that students with high levels of confidence in their academic abilities are more likely than students with low levels of confidence to engage in challenging academic tasks, persist on these tasks, and perform well on them (for reviews, see Schunk \& DiBenedetto, 2016; Wigfield, Tonks, \& Klauda, 2016). In addition, students who are confident about their abilities in a particular domain are more likely to value this domain, to register for courses in the domain, and to pursue domain-related majors (see Wigfield et al., 2016).

With respect to judgments of others' abilities, the extent to which students perceive their peers to have relatively high levels of ability can be either positively or negatively associated with their academic self-concept, motivation, and performance, depending on the context (see Wheeler \& Suls, 2005, for a review). For example, a student with a certain level of ability who attends a school where the average level of academic achievement is high will tend to have a more negative self-concept than a student with the same level of ability who attends a school where the average level of academic achievement is low (i.e., the big-fish-little-pond effect, Marsh et al., 2008). However, in other cases, comparing oneself to a student who receives relatively high grades or test scores is positively associated with future academic performance (Blanton, Buunk, Gibbons, \& Kuyper, 1999; Wehrens, Kuyper, Dijkstra, Buunk, \& Van der Werf, 2010), perhaps because upward comparisons may lead students to set more challenging goals for themselves. 
Given that students' evaluations of their own and others' abilities appear to play an important role in shaping their academic motivation, engagement, and performance, researchers have for decades been interested in understanding how these evaluations are formed (for reviews, see Cimpian, 2017; Muenks \& Miele, 2017). One of the conclusions that can be drawn from this research is that students base their judgments of ability, in part, on their perceptions of the amount of effort people expend attempting to complete academic tasks (e.g., Folmer et al., 2008; Karabenick \& Heller, 1976; Nicholls, Patashnick, \& Mettetal, 1986). However, not all students conceptualize the relation between levels of effort and ability in the same way. Some students tend to think of these factors as inversely related, such that the harder an individual works on a task, the less intellectual ability he or she must have. In contrast, others tend to perceive them as being positively related, such that high levels of effort indicate that the individual has a relatively high level of ability (for a review, see Muenks \& Miele, 2017).

What accounts for this difference in the ways that students reason about ability and effort? Much of the research attempting to answer this question has focused on one factor in particular: students' beliefs about whether ability is fixed or malleable (i.e., their ability mindsets). The goal of the present research was to expand the investigation to include a novel individual difference factor: students' beliefs regarding the nature or source of people's effort (i.e., their effort source beliefs). Building on prior experimental evidence (Muenks, Miele, \& Wigfield, 2016), we conducted three studies demonstrating that such beliefs can be reliably measured and that they predict students' judgments of their own and others' academic abilities across multiple academic domains.

\section{The Actual Relations Between Effort and Ability}

Before discussing students' perceptions of the relation between effort and ability, it is important to discuss the actual relations between these constructs. On the one hand, sustained 
mental effort can lead individuals to improve their intellectual skills and competence. This relation has been observed over both short and long periods of time. For instance, in a singlesession study, Fisher and Ford (1998) found that participants' self-reported mental effort during a learning task was positively associated with their subsequent application of the knowledge they had acquired. Moreover, research by Ericsson and colleagues (see Ericsson, 2006, for a review) has shown that extended periods of focused effort (in the form of "deliberate practice") can lead people to attain high levels of skill and ability in a particular domain, such as music or chess. Thus, there seems to be a causal relation between effort and ability, such that the amount of effort individuals expend over time positively impacts their level of competence or skill.

On the other hand, researchers have also demonstrated a causal relation in the other direction, whereby an individual's existing level of ability negatively predicts how much effort he or she has to expend in order to successfully complete a challenging task. Wright and colleagues have illustrated this relation with a financial investment metaphor: "We see lowability performers as possessing an effort currency that has less value than the currency of highability performers. Because low-ability currency has less value, more of it must be 'paid' (deployed) to make relevant 'purchases' (meet relevant challenges), raising the personal price of the purchase" (Wright, 2014; p. 186; see also Gendolla, Wright, \& Richter, 2012). Evidence for this negative relation between ability and effort comes from studies by Wright and colleagues (Stewart, Wright, Hui, \& Simmons, 2009; Wright, Patrick, Thomas, \& Barreto, 2013) in which they manipulated participants' levels of fatigue and then measured their effort in terms of systolic blood pressure responsiveness on a subsequent task. As explained by Wright (2014), "ability falls as fatigue rises," such that the highly fatigued individuals temporarily exhibited low levels of ability (p. 187). The results of the studies showed that participants exposed to the lowability induction (i.e., the high fatigue condition) subsequently expended higher levels of effort 
than participants exposed to the high-ability induction (i.e., the low fatigue condition), but only when they felt it was important to succeed at the task. When participants did not feel it was particularly important to succeed, the two groups of participants expended equivalent levels of effort. The latter finding suggests that the nature of the causal relation from ability to effort (i.e., whether or not it is negative) may depend in part on the extent to which individuals are motivated to engage in the task.

\section{The Perceived Relations Between Effort and Ability}

Critically, research examining students' reasoning about the relation between effort and ability has demonstrated that students are generally sensitive to both of the actual causal relations described in the previous section. In other words, students understand that effort can lead to the development of one's abilities; but, they also realize that one's current level of ability is inversely associated with how much effort one would have to expend in order to successfully complete a challenging task.

People's reasoning about the relation between effort and ability was initially explored in terms of attribution theory (e.g., Heider, 1958; Kelley, 1987). A central premise of this theory is that explaining one's successes or failures in terms of effort versus ability can lead one to experience different emotions and exhibit different motivational tendencies. In an early version of attribution theory, Heider (1958) specified two aspects of a concept that he called "trying": a directional aspect which takes the form of an intention and a quantitative aspect which is expressed in terms of exertion. According to Heider, the extent to which a person exerts herself on a task is inversely correlated with her ability, such that if two people are working on the same task, the one who completes it with less effort is perceived as having more ability. Kelley (1987) made a similar claim as part of his version of attribution theory. 
Critically, however, developmental psychologists have found that while nearly all children eventually become aware of the inverse relation between effort and ability, children (and adults) do not necessarily apply this logic in all situations (for reviews, see Cimpian, 2017; Muenks \& Miele, 2017). Specifically, Nicholls and colleagues have found that whether or not an individual will perceive ability to be inversely related to effort is, in part, dependent on how he or she currently conceptualizes ability, which in turn depends on the nature of the social context (see Jagacinski \& Nicholls, 1984, 1987). When students are in an academic context that emphasizes social comparison, they tend to conceptualize ability as a stable capacity that is negatively associated with the amount of effort needed to successfully complete a challenging task. However, when they instead find themselves in a context that emphasizes individual growth or mastery, they are more likely to conceptualize ability as a competence or set of skills that develops with increasing effort.

Research by Dweck and colleagues has also attempted to explain how students think about the relation between effort and ability in terms of the ways in which they conceptualize ability. However, as opposed to examining how students' ability conceptions vary across social contexts, Dweck has explored stable individual differences in people's beliefs about ability and intelligence that lead students to broadly adopt a particular conception (or mindset) across multiple contexts. According to Dweck, students who believe that intelligence is fixed after a certain point in development and cannot be changed exhibit a fixed mindset, whereas students who believe that intelligence is malleable and can be improved over time exhibit a growth mindset. Importantly, studies suggest that students with a fixed mindset may be more likely than students with a growth mindset to perceive high levels of effort as indicating low levels of ability (e.g., Blackwell, Trzesniewski, \& Dweck, 2007; Hong, Chiu, Dweck, Lin, \& Wan, 1999; Miele, 
Son, \& Metcalfe, 2013). Thus, like Nicholls's work, Dweck's research suggests that students are generally sensitive to the negative and positive relations that exist between effort and ability.

Although Nicholls's situational and developmental approach to studying students' reasoning about the relation between effort and ability differs in important ways from Dweck's individual difference approach, they both distinguish between beliefs about the nature of ability (as a fixed capacity versus a set of malleable skills) and beliefs about the level/amount of ability one possesses. Furthermore, they both demonstrate that beliefs about the nature of ability (e.g., ability mindsets) influence how students interpret the relation between the level of effort someone expends during a task and that person's level of ability. However, the interpretation of this relation may depend not only on one's beliefs about the nature of ability, but also on one's beliefs about the nature of effort. Thus, to more fully understand how students think about the relation between levels of effort and ability, we must also explore their effort conceptions. In the next section, we review research that has begun to explore how students' conceptions of effort (and in particular, their perceptions of the source from which effort is derived) influence whether they perceive ability level to be positively or negatively related to effort level.

\section{Perceptions of Effort Source}

As previously discussed, Heider proposed that individuals view the act of "trying" as involving both an intention (which gives direction to the trying) and a level of exertion that is aimed at fulfilling this intention. Until recently, researchers focused primarily on students' perceptions of exertion, without accounting for their perceptions of the intentions from which this exertion arises. Building upon Heider's notion of intentional effort, Muenks and Miele (2017; Muenks et al., 2016) have argued that students' interpretations of someone's effort depend in part on whether they perceive this effort to be an automatic response to the basic demands of the task (i.e., the minimal demands that must be met in order to successfully 
complete the task) or as resulting from the motivation (and intention) to engage more deeply in the task. When students perceive effort as an automatic response, they view it as having been elicited by the subjective difficulty of the task (i.e., as task-elicited effort). This, in turn, leads them to interpret high levels of effort as a sign that the individual had to work hard in order to compensate for low levels of ability. In contrast, when students perceive effort as resulting from one's desire to work hard (i.e., as self-initiated effort), they associate it with present or future mastery and, therefore, do not view it as a sign of low ability. In fact, to the extent that students believe that intelligent and high achieving students are motivated to work hard or that hard work leads to intellectual growth, they may even interpret self-initiated effort as a sign of high ability.

The distinction between task-elicited and self-initiated effort is based, in part, on prior research in the metacognition literature by Koriat and colleagues (see Koriat, Ackerman, Adiv, Lockl, \& Schneider, 2014; Koriat, Ma’ayan, \& Nussinson, 2006). These researchers proposed that the association between the amount of effort that participants spend memorizing content (e.g., particular word pairs) and how confident they are about being able to later recall this content (operationalized as "judgments of learning") depends on whether the effort is part of data-driven versus goal-driven regulation. When engaged in data-driven regulation, individuals monitor how much effort they had to expend in order to memorize or encode something, with high levels of effort indicating that the material was difficult to learn. In other words, effort is perceived as being task-elicited. And, to the extent that these individuals also believe that difficult material is less likely to be remembered, they should interpret high effort as a sign of poor learning and exhibit an inverse relation between their processing effort and their metacognitive judgments. Consistent with this proposal, Koriat and colleagues (2006) demonstrated that the amount of time (and presumably effort) participants spent studying word pairs was negatively associated with their judgments of learning. 
By contrast, when individuals are instead engaged in goal-driven regulation, they use effort as a tool to deliberately pursue a particular goal, such that they spend relatively more time studying items that they perceive as potentially important or useful to learning. In other words, effort is perceived as being self-initiated. And to the extent that they perceive this effort as leading to better encoding, individuals should view high effort a sign of good learning and, thus, exhibit a positive relation between their encoding effort and their metacognitive judgments. Evidence for this claim comes from a study in which the incentives provided to participants for learning different word pairs varied in magnitude (Koriat et al., 2006). Not only did the participants spend more time studying the high incentive items compared to the low incentive items, they were also more confident (i.e., had higher judgments of learning) about being able to recall them on an upcoming test. Overall, Koriat's research suggests that the perceived meaning of effort during self-regulation — either as task-elicited during data-driven regulation or as selfinitiated during goal-driven regulation - influences how people think about the relation between effort and learning.

The distinction between task-elicited and self-initiated effort is also based on prior research from the developmental literature by Heyman and colleagues (Heyman \& Compton, 2006; Heyman, Gee, \& Giles, 2003). In one study (Heyman \& Compton, 2006, Study 1), kindergarteners and elementary school children were presented with a hypothetical scenario in which one character was described as having finished a set of puzzles very quickly and another character was described as having finished the puzzles slowly. In the generic "effort" condition, the children were told that the quick character "hardly tried at all" whereas the slow character "tried and tried." In the "perceived difficulty" condition, the children were instead told that the quick character "thought the puzzles were easy to do" while the slow character "thought the puzzles were hard to do." The children were then asked to assess which of the characters was 
smarter. The results showed that, for the older children, those in the generic effort condition tended to think that the slow character was smarter on average (thus, perceiving a positive relation between effort and ability), whereas those in the perceived difficulty condition tended to think that the quick character was smarter (thus, perceiving an inverse relation). This finding suggests that information about why someone worked hard can change students' views about how this effort relates to ability. When effort is described as originating from the difficulty of the task (as being task-elicited), it leads students to think in terms of an inverse relation between effort and ability. However, when effort is not described in terms of difficulty (and thus could potentially originate from some other source), students do not necessarily think in terms of an inverse relation.

Building on this research by Heyman, Koriat, and colleagues, Muenks, Miele, and Wigfield (2016) directly contrasted college students' perceptions of task-elicited effort with their perceptions of self-initiated effort. Specifically, they had students read a series of vignettes in which hypothetical characters were described as working on a class assignment. Some characters were described as putting in more effort than the others, and the source of this effort was framed as being either self-initiated or task-elicited. Results indicated that when effort was framed as task-elicited (e.g., when one character was said to put in more effort because she found the task more difficult than the other character did), and performance information was not included, student were more likely to rate the high-effort characters as having less ability than the characters who put in less effort (i.e., an inverse relationship between effort and ability). By contrast, when effort was described as self-initiated (e.g., when one character was said to put in more effort because she was more motivated to engage in the task), participants were less likely to perceive an inverse relation and, in some cases, even perceived a positive relation between 
effort and ability. Furthermore, this pattern of results was observed across content domains (math, English literature, and physics).

\section{Research Questions}

At this point, research on perceived effort source has examined task-elicited versus selfinitiated effort as a variable that can be experimentally manipulated by highlighting a person's reasons for working hard (or not working hard). However, it is still unclear whether students spontaneously draw on their own beliefs about effort source when forming judgments of ability. This gap in the literature led us to pose the following research questions.

\section{Primary Research Questions}

First, do college students have general beliefs about whether effort in a particular academic domain (e.g., math or English) tends to be task-elicited or self-initiated, and can these beliefs be reliably assessed? To answer this question, we developed and refined a novel measure of effort source beliefs that was used in all three of the present studies.

Second, in the absence of strong situational cues, do these effort source beliefs influence how students think about the relation between levels of effort and ability? In particular, do they influence students' judgments of ability when they are provided with information about how hard someone worked on an academic task? Based on prior research (Muenks et al., 2016), we expected that students with a tendency to perceive effort as task-elicited would view levels of effort as inversely related to levels of ability and, thus, would judge a student who worked hard on an assignment to have less ability than a student who did not work hard. In contrast, we expected that students with a tendency to perceive effort as self-initiated would be less likely to view levels of effort as inversely related to levels of ability and, in some cases, might even view these constructs as positively related to each other.

\section{Secondary Research Questions}


In addition to these primary research questions, we were interested in exploring three other questions. First, do students draw on their effort source beliefs when forming judgments of their own ability, in addition to forming judgments of other people's abilities? Specifically, is the pattern of association between effort source beliefs and ability judgments the same in self- and other-oriented contexts? Second, can effort source beliefs be reliably measured in multiple academic domains (e.g., math and English)? And, are effort source beliefs in each of these domains predictive of students' ability judgments, or is effort source more salient as an ability cue in one domain than in another?

Finally, to what extent are students' effort source beliefs - that is, their beliefs about the nature of effort - correlated with their ability mindsets — their beliefs about the nature of ability? And, do effort source beliefs and growth mindsets independently predict students' ability judgments? On the one hand, it seems intuitively plausible that the two constructs could be related. For example, it is easy to imagine a student with a fixed mindset who believes that individual differences in innate ability account for how much more effort some people (versus others) must put into academic tasks in order to be successful. Such a student may be particularly likely to view effort as task-elicited. On the other hand, there is no logical reason why the two types of beliefs must be related. For instance, it is also easy to imagine a student with a fixed mindset who believes that people who are innately intelligent (compared to people who are not) tend to be more interested in intellectual pursuits and thus are particularly motivated to expend effort on academic tasks. Such a student would be likely to view effort as self-initiated. Conversely, imagine an individual with task-elicited beliefs about effort who infers that students who work hard on school tasks do so because they have low levels of ability and the tasks are subjectively difficult for them. This individual could believe either that (a) the tasks will always 
be difficult for the students (a fixed mindset) or (b) the students will eventually find math to be less challenging than they do now (a growth mindset).

\section{Present Studies}

We conducted three studies to address our research questions. In each study, college participants were presented with several vignettes in which a student was described as working hard or not working hard. For each vignette, participants were asked to rate how much ability they believed the student to possess. Unlike in the studies by Muenks et al. (2016), the vignettes did not provide any information about why the student put forth a certain amount of effort. After responding to the vignettes, the participants completed a novel measure of their effort source beliefs. In Study 1, both the vignettes and the effort source beliefs measure were about the efforts of other students in the context of a math course. In Study 2, which was also focused on the math domain, participants were presented with two types of vignettes (half were about other students and half were about themselves) and two belief measures (one about other students and another about themselves). In Study 3, we explored the effects of effort source beliefs in a second academic domain by framing the vignettes and the effort beliefs measure in the context of an English course.

\section{Study 1}

The goal of Study 1 was to begin to address our primary research questions. That is, do college students have general beliefs about whether effort in a particular academic domain (i.e., math) tends to be task-elicited or self-initiated, can these beliefs be reliably assessed, and are these effort source beliefs associated with how students think about the relation between levels of effort and ability? As such, participants in Study 1 responded to four vignettes, each involving a student who was described as working hard (two vignettes) or not working hard (two vignettes) on a math assignment. Participants were asked to evaluate the ability of each student. 
Participants then completed our effort source beliefs measure. Finally, to examine the relations between students' effort source beliefs and their ability mindsets, participants also completed a measure of their ability mindsets.

\section{Participants}

Data were collected from 110 participants who were recruited from sections of a course on child development (spring 2016) in the school of education at a private research university in Massachusetts (see Table 1 for demographics). These participants completed studies to fulfill a research requirement for the course. The sample provided a statistical power of .80 to detect an interaction effect of $f^{2} \geq .073 .^{1}$

\section{Procedure and Methods}

Participants completed the measures described below in the order in which they are listed. Information about the internal consistency reliability for each measure is reported in Table 2, along with descriptive statistics. See the supplementary materials for a description of additional materials not discussed herein (including some items that were administered before the ability mindset measure).

Judgments of ability. Participants were first presented with four vignettes (in a random order) that were about hypothetical students completing math assignments in a calculus or linear algebra class. In these and all subsequent vignettes (Studies 1-3), the characters were given female names in order to match the high proportion of females in our samples. Each vignette featured a single student (e.g., Jennifer or Cassidy), and the student was described as putting in a high level of effort in two of the vignettes (e.g., "The class is given 15 minutes to complete the assignment, and Jennifer spends the full 15 minutes on the problems, concentrating hard, and

\footnotetext{
${ }^{1}$ We initially analyzed data from 80 participants. Because the primary interaction effect was not significant, we collected data from an additional 30 participants to address a possible lack of power.
} 
putting in a lot of effort"), and as putting in a low level of effort in the remaining two (e.g., "The class is given 15 minutes to complete the assignment, and Cassidy spends only 10 minutes on the problems, putting forth relatively little effort"). See the Appendix for full versions of all four vignettes.

After reading each vignette, participants were asked to evaluate the student's math ability on a 6-point scale ("Very Low" to "Very High," with the intermediate points also labeled). For the purposes of analysis, we computed two ability judgment variables: one variable represented the mean judgment for the two high effort vignettes and the other variable represented the mean judgment for the two low effort vignettes. It is important to note that in all three studies, participants made their ability judgments before indicating their effort source beliefs, thereby ruling out the possibility that their judgments were based on externally primed effort source beliefs.

Effort source beliefs. Participants' effort source beliefs in the math domain were assessed using a vignette-based measure. Each vignette described two hypothetical students in a math class who were completing the same assignment individually, with one of the students described as putting in more effort than the other-for example:

"Two college students, Sarah and Lisa, are sitting in a Math class. The professor gives the class an assignment to work on individually. Sarah works hard on the assignment, while Lisa does not work very hard."

For each vignette, participants used a 6-point scale to indicate how likely it was ("Very Unlikely" to "Very Likely") that the student who worked harder did so for task-elicited reasons and how likely it was that the student did so for self-initiated reasons (see Table 3 for a list of items). Participants completed six such vignettes, displayed in random order, with the two response items for each vignette presented in a random order on the same screen. See the Appendix for full versions of all six vignettes. An exploratory factor analysis (EFA) produced a 
clean factor structure, with all task-elicited beliefs items loading onto one factor, all self-initiated beliefs items loading onto a second factor, and no cross-loadings (see Table 3). See the supplementary materials for complete description of the EFA. For measures of internal consistency reliability, see Table 2 .

Across all of our studies, we were primarily interested in assessing the relative (rather than the absolute) strength of participants' effort source beliefs. In other words, although the EFA suggests that the strength of participants' task-elicited and self-initiated beliefs vary independently, people's ability judgments should in part be determined by the predominant strength of one set of beliefs over the other. This is in keeping with analyses of other multi-factor individual difference constructs (e.g., Molden \& Winterheld, 2013; Sheldon, Osin, Gordeeva, Suchkov, \& Sychev, 2017). As such, participants' effort source belief scores were calculated by subtracting their mean judgment of self-initiated effort from their mean judgment of task-elicited effort (both means are reported in Table 2, along with the mean difference score). In this coding scheme, positive scores reflect a general tendency to perceive other people's efforts as taskelicited, with higher scores reflecting stronger task-elicited tendencies. Conversely, negative scores reflect a tendency to perceive these efforts as self-initiated, with lower scores reflecting stronger self-initiated tendencies. Interestingly, the mean of the scores $(M=.24, S D=.76$, skewness $=.49$, kurtosis $=1.71)$ was significantly greater than zero, $t(109)=3.34, p=.001$, Cohen's $d=.32$, indicating a general tendency of participants to think in terms of task-elicited effort in the math domain.

Ability mindsets. Participants also completed a validated measure of ability mindsets (Dweck, 2000), which allowed us to examine the contributions of effort source beliefs above and beyond those of an established predictor of students' ability judgments. The scale included four growth mindset items (e.g., "You can always substantially change how intelligent you are") and 
four fixed mindset items (e.g., You have a certain amount of intelligence, and you really can't do much to change it). Participants responded using a 1 (Strongly Disagree) to 6 (Strongly Agree) scale. Fixed mindset items were reverse coded and ability mindset scores were computed by averaging across all eight items, with higher scores indicating that a participant had a stronger growth mindset about intelligence.

\section{Results}

The correlation between participants' effort source beliefs and their ability mindsets was small and non-significant, $r(108)=-.05, p=.576$, suggesting that these variables represent distinct constructs.

To test whether our novel measure helps account for variation in students' ability judgments, we submitted these judgments to a repeated measures ANCOVA in R with Type III sum of squares. This analysis included the target's effort level (high versus low) as a dichotomous within-subjects factor, participants' standardized effort source belief scores as a continuous covariate, and target's effort level $\times$ effort source beliefs as the interaction term. In addition, to test whether the effects of our measure were independent of the effects of ability mindsets, we entered participants' standardized mindset scores and the effort level $\times$ ability mindset interaction term as additional predictors in a second step. We conducted an ANCOVA instead of a linear regression analysis because ANCOVA, unlike regression, allowed us to examine the interaction between a continuous independent variable (i.e., the covariate) and a repeated-measure factor (see Algina, 1982; Thomas, 2009; Thomas et al., 2009, for more detail on this analytic approach).

The results of the analysis are displayed in Table 4 and Figure 1. Replicating prior work (e.g., Folmer et al., 2008; Karabenick \& Heller, 1976; Nicholls et al., 1986), a negative main effect of effort level on students' ability judgments appeared. That is, for participants who scored 
at the mean of the effort source scale, greater effort was seen as indicative of lower academic ability. ${ }^{2}$ More critically, this main effect was significantly moderated by students' effort source beliefs. Simple effects analyses conducted at $1.5 S D$ above and below the mean of the scale revealed that, for students with relatively strong task-elicited beliefs (+1.5 SD), targets who put in less effort were judged to have higher ability than those who put in more effort. By contrast, students with relatively strong self-initiated beliefs $(-1.5 S D)$ did not perceive effort and ability as inversely related when evaluating other students' ability levels. This difference between students with task-elicited and self-initiated beliefs was driven primarily by their perceptions of the low effort targets. That is, students with task-elicited beliefs rated the low effort target's math ability higher than did students with self-initiated beliefs. The non-significant difference for the high effort target was in the opposite direction. ${ }^{3}$

Importantly, the effort source $\times$ effort level interaction remained significant when the additional predictors were included in the model, whereas the ability mindsets $\times$ effort level interaction was not significant. ${ }^{4}$ Finally, the overall pattern of results did not differ based on whether outliers were included or excluded from the effort source and ability mindset variables (see the supplementary materials for the results of analyses conducted with outliers excluded). ${ }^{5}$

\section{Discussion}

\footnotetext{
${ }^{2}$ Because all terms (including the interaction) were added to the model simultaneously, the main effect of effort level represents the effect of this variable when the standardized effort source score is equal to zero (see Aiken \& West, 1991).

${ }^{3}$ We conducted these analyses at $\pm 1.5 S D$ to be consistent with our prior work on mindsets (e.g., Miele et al., 2013).

${ }^{4} 102$ of the 110 participants in this study also completed a measure of their math-specific ability mindsets (Leslie, Cimpian, Meyer, \& Freeland, 2015) as part of a separate study which they completed 21-51 days later. The correlation between participants' effort source beliefs and their math-specific ability mindsets was small, $r(100)$ $=-.20, p=.043$, and including these mindsets in our analyses instead of their domain-general mindsets did not alter our results (effort source $\times$ effort level interaction: $F(1,99)=8.72, p=.004, \eta^{2}{ }^{2}=.081$ ). See the supplementary materials for complete details regarding the math-specific mindsets measure and analyses for this study and for Study 3.

${ }^{5}$ Across studies, the number of participants with outlier scores $( \pm 3 S D)$ excluded in each of our primary analyses ranged from 1 to 2 .
} 
Study 1 was designed to examine two central research questions: Can effort source beliefs be reliably measured? And, do these beliefs predict participants' judgments of other students' abilities? Regarding the first question, the results of the study showed that our novel measure of effort source beliefs had good psychometric properties. Participants' scores on this measure indicate that, on average, they tended to interpret effort in the math domain as being task-elicited. This is consistent with attitudes and stereotypes in the U.S. regarding the difficulty of mathematics: because it is commonly believed that "math is hard" (Ashcraft, 2002; Saad, 2005), students may come to perceive the effort that people expend during math activities as being directly elicited by the difficulty of the task. At the same time, however, there was a fair amount of variability in the extent to which participants perceived effort as being more taskelicited versus more self-initiated.

Regarding the second question, we found that participants who scored at the mean of the effort source scale viewed higher levels of effort as indicative of lower levels of academic ability. This main effect can partly be explained by the fact that participants who scored at the mean of the effort source measure held task-elicited beliefs. However, an additional analysis showed that even participants who scored at the midpoint of the scale may have viewed higher levels of effort as a sign of low ability, $t(108)=-1.72, p=.089$. This tendency to view effort and ability as inversely associated perhaps makes sense when you consider that math assignments typically consist of close-ended problems, with students being rewarded for finding the one right answer as quickly as possible. That is, regardless of their effort source beliefs, participants may view people who complete math tasks quickly as being top performers and, in turn, view top performers as having high levels of math ability.

More importantly, we found that (in line with out expectations) the main effect of effort level was moderated by participants' effort source beliefs. Specifically, participants who tended 
to perceive effort as task-elicited judged the students in the vignettes who worked hard as having less math ability than the students who did not work hard - they viewed effort as inversely related to ability. In contrast, participants who tended to perceive effort as self-initiated judged the students who worked hard as having just as much ability as students who did not work hard - they did not view effort as inversely related to ability.

Finally, we explored two questions regarding the association between effort source beliefs and ability mindsets. First, we found that there was no correlation between these constructs. Second, only effort source beliefs emerged as a significant predictor of participants' ability judgments when examining these beliefs and ability mindsets simultaneously.

The finding that effort source beliefs influence students' judgments of others' abilities has important implications for research on academic motivation. As discussed, the extent to which students perceive their peers to have relatively high levels of ability in a particular domain can contribute to their motivation in that domain. However, the relation between judgments of other students' abilities and one's own motivation is, perhaps, less direct and weaker than the relation between self-judgments of ability and one's own motivation. Therefore, it is important to examine whether students' effort source beliefs predict their assessments of their own abilities, in addition to their assessments of others' abilities (see Muenks, 2016).

\section{Study 2}

Study 2 was designed to provide further evidence for our primary research questions: do college students have general beliefs about whether effort in a particular academic domain (i.e., math) tends to be task-elicited or self-initiated, can these beliefs be reliably assessed, and do these effort source beliefs influence how students think about the relation between levels of effort and ability? As such, Study 2 directly replicated the methods used in Study 1. 
Additionally, Study 2 sought to extend our findings from Study 1 to self-judgments of ability. That is, do college students have general inclinations regarding whether their own efforts tend to be task-elicited or self-initiated, and do these effort source beliefs influence how they think about the relation between their own levels of effort and their own abilities? As such, participants in Study 2 initially completed a series of vignettes that were either about themselves or another student exhibiting high or low levels of effort on a math assignment. After assessing the math ability of another student or themselves in each vignette, participants completed two versions of the effort source beliefs measure. One version assessed their effort source beliefs in regard to other individuals (replicating Study 1), while the other version assessed the same beliefs in regard to themselves. As in Study 1, all participants also completed a measure of their growth mindsets.

\section{Participants}

Data were collected from 185 participants who were recruited from a course on child development (fall 2017) in the school of education at a private research university in Massachusetts. These participants completed studies to fulfill a research requirement for the course (see Table 1 for demographics). Responses from 5 participants were removed because they had previously participated in one of the other studies reported herein. The final sample of 180 participants provided a statistical power of .80 to detect an interaction effect of $f^{2} \geq .044$.

\section{Procedure and Methods}

The procedure in Study 2 was the same as in Study 1, except that half of the materials were framed in terms of other people (as in Study 1) and half were framed in terms of the participants themselves. Specifically, participants first responded to eight ability judgment vignettes in a random order: the same four from Study 1 in which they evaluated the ability levels of other students who were described as having exerted high or low levels of effort, and 
four new vignettes in which they evaluated their own ability levels after imagining that they had exerted high or low effort. Again, participants made their ability judgments before indicating their effort source beliefs, thereby ruling out the possibility that their judgments were based on externally primed effort source beliefs.

Next, participants completed two six-vignette effort source belief measures, in a random order. One was the same measure used in Study 1, in which the vignettes involved two hypothetical students, with one described as exerting a greater amount of effort than the other. The second measure included vignettes that involved both the participant themselves and one hypothetical other student, with the participant being described as exerting more effort than the hypothetical student in three of the vignettes and less effort in the other three. Finally, they completed the same ability mindset measure as in Study 1. The new, self-focused materials used in Study 2 are described below.

Self-judgments of ability. In addition to the four vignettes used in Study 1, which involved fictional students completing math assignments, participants were also presented with four hypothetical vignettes that involved the participants themselves-for example, "Imagine that you are sitting in a Linear Algebra class that you enrolled in when the professor gives the class a set of problems to work on individually." Participants were described as putting in a high level of effort in two of the vignettes (e.g., "The class is given 18 minutes to complete the assignment, and you spend the full 18 minutes on the assignment, concentrating hard, and putting in a lot of effort"), and as putting in a low level of effort in the remaining two (e.g., "The class is given 18 minutes to complete the assignment, and you spend only 12 minutes on the assignment, putting forth relatively little effort"). See the Appendix for full versions of all four vignettes. After reading each vignette, participants evaluated their own math ability on a 6-point scale ("Very Low" to "Very High"). For the purposes of analysis, we computed two ability 
judgment variables: one variable represented the mean self-judgment for the two high effort vignettes and the other variable represented the mean self-judgment for the two low effort vignettes.

Self-relevant effort source beliefs. In addition to the measure used in Study 1, participants completed a second measure of their effort source beliefs. In this new measure, each vignette described a hypothetical student and the participant themselves completing the same assignment individually, with one of them described as putting in more effort than the other-for example:

"You and another student, Lisa, are sitting in a Math class. The professor gives the class an assignment to work on individually. You work hard on the assignment, while Lisa does not work very hard."

For each vignette, participants used a 6-point scale to indicate how likely it was ("Very Unlikely" to "Very Likely") that the student who worked harder did so for task-elicited reasons (e.g., "you found the assignment to be difficult, whereas Lisa found the assignment to be easy") and how likely it was that the student did so for self-initiated reasons ("you were motivated to perform well on the assignment, whereas Lisa was not motivated to perform well’). Participants completed six such vignettes, displayed in random order, with the two response items for each vignette presented in a random order on the same screen (see Appendix). In three of the vignettes, the participant was described as putting in more effort than the hypothetical student; and, in the other three, he or she was described as putting in less effort.

Participants' effort source belief scores for both measures (other-focused and selffocused) were calculated as in Study 1, by subtracting their mean judgment of self-initiated effort across the six vignettes from their mean judgment of task-elicited effort. In this coding scheme, positive scores reflect a general tendency to perceive both other people's and participants' own efforts as task-elicited, with higher scores reflecting stronger task-elicited tendencies. 
Conversely, more negative scores reflect a tendency to perceive these efforts as self-initiated, with lower scores reflecting stronger self-initiated tendencies. The mean scores for both measures (other-focused: $M=.38, S D=.83$, skewness $=.43$, kurtosis $=1.55$; self-focused: $M=$ $.71, S D=.92$, skewness $=.60$, kurtosis $=.92)$ were significantly greater than zero, $t \mathrm{~s}(179)>6.23$, $p s<.001$, Cohen's $d s=.47$ (other-focused) and .78 (self-focused), indicating a general tendency of participants to think in terms of task-elicited effort. Furthermore, participants reported significantly stronger task-elicited beliefs when describing their own efforts than when describing those of others, $t(179)=6.68, p<.001$, Cohen's $d=.50$. Finally, the two measures were highly correlated, $r(178)=.72, p<.001$.

\section{Results}

Similar to Study 1, the correlations between participants' ability mindsets and both effort source belief measures were small, $r(178)=-.13, p=.094$ (other-focused), $r(178)=-.05, p=$ .531 (self-focused), further supporting our contention that these variables represent distinct constructs.

To test whether the results of Study 1 were replicated in Study 2, we submitted participants' judgments of others' abilities to a repeated measures ANCOVA that included the target's effort level (high versus low) as a dichotomous within-subjects factor, participants' standardized effort source belief scores as a continuous covariate, and target's effort level $\times$ effort source beliefs as the interaction term. In addition, to test whether the effects of our measure were independent of the effects of ability mindsets, we entered participants' standardized mindset scores and the effort level $\times$ ability mindsets interaction term as additional predictors in a second step. As shown in the Table 5a and Figure 2a, the results of this analysis replicated the results from Study 1. In fact, the pattern of means for the effort level $\times$ effort source interaction was almost identical across the two studies. 
To examine participants' self-judgments of ability, we conducted a second set of repeated measures ANCOVA analyses, with self-focused effort source beliefs scores included instead of other-focused scores. As shown in Table $5 \mathrm{~b}$ and Figure $2 \mathrm{~b}$, the results of this analysis were very similar to the results of the other-focused analyses. Specifically, we observed a negative main effect of effort level on participants' self-judgments of ability. In other words, high levels of effort by others or by the self were seen as indicating relatively low levels of math ability by participants who scored at the mean of the effort source scales. Participants who scored at the midpoint of the other-oriented scale exhibited the same pattern, $t(178)=-2.13, p=.034$; however, participants who scored at the midpoint of the self-oriented scale did not, $t(178)=$ $1.28, p=.201$

More critically, these effects were significantly moderated by participants' self-focused effort source beliefs. To explore the interactions, we conducted simple effects analyses at $1.5 S D$ above and below the mean of the effort source measure. In line with the other-focused findings, participants with relatively strong task-elicited beliefs $(+1.5 S D)$ rated their own abilities to be lower when they imagined themselves expending high versus low levels of effort (i.e., an inverse relation between ability and effort). In contrast, students with relatively strong self-initiated beliefs $(-1.5 S D)$ evaluated their ability to be the same across the two effort level conditions. Similar to the other-focused analyses (both in the current study and in Study 1), students with task-elicited beliefs rated their math ability for the low effort vignettes marginally higher than did students with self-initiated beliefs (though this difference was not significant when outliers were excluded; see Table S2b). However, in contrast to the other-focused analyses, we found a significant effect of effort source beliefs in the opposite direction for the high effort vignettes. Finally, the self-focused effort source $\times$ effort level interaction remained significant when the 
additional predictors were included in the model, whereas the ability mindsets $\times$ effort level interaction was not significant.

\section{Discussion}

Replicating the results of Study 1, we found that the participants in Study 2 who tended to perceive effort as task-elicited judged other students who worked hard as having less math ability than the students who did not work hard. In contrast, participants who tended to perceive effort as self-initiated did not view effort as inversely related to math ability. Extending these results, we found a similar pattern when examining participants' judgments of their own math ability. The main difference was that, when imagining themselves working hard, participants who tended to view effort as task-elicited rated their own ability significantly lower than participants who viewed effort as more self-initiated. And, although there were signs of an effect in the opposite direction when participants imagined themselves not working particularly hard, this effect was, at most, only marginally significant.

With respect to participants' ability mindsets, Study 2 replicated the results of Study 1. Specifically, the correlations between participants' ability mindsets and effort source beliefs were either weak or non-significant and only the effort source beliefs emerged as a significant predictor of participants' self- and other-oriented ability judgments when examining these beliefs and ability mindsets simultaneously.

While the findings of Studies 1 and 2 were remarkably similar, it remains to be seen whether this pattern of results extends to an academic domain other than mathematics. Just as people's mindsets about different academic abilities appear to be distinct (e.g., math vs. language ability; Lou \& Noels, 2016; Muenks, Miele, Ramani, Stapleton, \& Rowe, 2015), it seems plausible that students' effort source beliefs might vary across academic domains. This variability could emerge in at least two ways. First, participants' mean effort source beliefs in 
one domain may be more task-elicited or self-initiated than their beliefs in another domain. Second, the strength or direction of the association between effort source beliefs and ability judgments may differ from one domain to the next. We tested these possibilities in Study 3.

\section{Study 3}

Study 3 was designed to replicate the findings of Studies 1 and 2, while extending them to the verbal domain. While the tendency of students in the first two studies to view math effort as being task-elicited is consistent with attitudes and stereotypes in the U.S. regarding the difficulty of mathematics (Ashcraft, 2002; Saad, 2005), beliefs about English being a difficult subject may be less commonplace. Although we made no a priori predictions, this line of reasoning suggests that students may be less likely to perceive verbal effort (compared to math effort) as being task-elicited.

To extend our findings to the verbal domain, we framed the ability judgments vignettes and effort source beliefs measure in terms of an English class rather than a math class. Similarly, as opposed to being asked to assess the math ability of the students in the vignettes, participants were asked to assess their verbal ability. Finally, as in Studies 1 and 2, participants also reported their ability mindsets.

\section{Participants}

Responses were collected from 185 participants who were recruited over three semesters (spring 2016, fall 2016, and spring 2017) from sections of two different courses on child development in the school of education at a private research university in Massachusetts. These participants completed studies to fulfill a research requirement for the course. One participant appeared to complete the study twice and had their second set of responses removed, leaving responses from 184 participants for analysis (see Table 1 for demographics). This provided a statistical power of .80 to detect an interaction effect of $f^{2} \geq .043$. 


\section{Procedure and Materials}

The design of the study was identical to that of Study 1, with the exception of the academic domain of focus. The ability judgment task included vignettes that focused on a writing assignment in the context of an English literature or English composition class_-for example:

"Amy, a college student, is sitting in her English Composition class when the professor gives the class a writing assignment to work on individually. The class is given 18 minutes to complete the assignment, and Amy spends the full 18 minutes on the assignment, concentrating hard, and putting in a lot of effort."

For each vignette, participants were asked to rate the student's "verbal ability.” Again, participants made their ability judgments before indicating their effort source beliefs.

Similar to the ability judgment task, the effort source measure included vignettes set in the context of an English class - for example:

"Two college students, Diane and Rachel, are sitting in an English class. The professor gives the class an assignment to work on individually. Diane finishes the assignment in 15 minutes, while Rachel finishes in 10 minutes."

As in Studies 1 and 2, participants used a 6-point scale to indicate how likely it was (from "Very Unlikely" to "Very Likely") that the student who worked harder did so for task-elicited reasons and how likely it was that the student did so for self-initiated reasons. Participants completed six such vignettes, displayed in random order, with the two response items for each vignette appearing on the same screen in a random order. Participants' effort source belief scores were calculated as in Study 1, by subtracting their mean judgment of self-initiated effort from their mean judgment of task-elicited effort. Interestingly, the mean of the scores $(M=-.08, S D=.73$, skewness $=-.71$, kurtosis $=1.78)$ was not significantly different from zero, $t(183)=-1.45, p=$ $.150, d=.11$. That is, contrary to our findings from a math context (Studies 1 and 2), participants 
in a verbal context did not tend to perceive the source of other students' effort as task-elicited on average.

\section{Results}

As in Studies 1 and 2, the correlation between participants' ability mindsets and their verbal-focused effort source beliefs was small and non-significant, $r(182)=-.07, p=.330$. This further supports our contention that ability mindsets and effort source beliefs represent distinct constructs, even when examining effort source beliefs in a second domain.

To test the association between participants' effort source beliefs and their judgments of verbal ability, we submitted these judgments to a repeated measures ANCOVA that included the target's effort level (high versus low) as a dichotomous within-subjects factor, participants' standardized effort source belief scores as a continuous covariate, and target's effort level $\times$ effort source beliefs as the interaction term. In addition, to test whether the effects of our measure were independent of the effects of ability mindsets, we entered participants' standardized mindset scores and the effort level $\times$ ability mindsets interaction term as additional predictors in a second step.

The results are displayed in Table 6 and Figure 3. In contrast to the negative main effect observed in the math domain in Studies 1 and 2, we observed a strong, positive main effect of effort level on participants' verbal ability judgments. That is, for participants who scored at the mean of the effort source scale in the verbal domain, students who expended high levels of effort were viewed as having more verbal ability than students who expended low levels of effort. The same was true for participants who scored at midpoint of the scale, $t(182)=9.57, p<.001$. However, consistent with Studies 1 and 2, this main effect was significantly moderated by participants' verbal effort source beliefs (though this interaction dropped to marginal significance $[p=.058]$ when excluding outliers in the predictor variables [see Table S3]). 
Furthermore, the pattern of the interaction was again driven by participants' perceptions of the low effort targets. As in the previous two studies, participants with task-elicited effort source beliefs (1.5 SD above the mean of the effort source scale) rated the low effort target's verbal ability higher than did participants with self-initiated beliefs (1.5 $S D$ below the mean). For the high effort target, there was a non-significant trend in the opposite direction. In other words, the direction and significance of these simple effects were generally consistent across all three studies, which can be verified by visually comparing the magnitude and direction — rather than the intercept - of each slope across Figures 1-3 (also see the statistics for the simple effects in Tables 4-6).

By contrast, what did vary considerably between the results of the present study and those of the previous two studies was the intercept of each effort source slope. Specifically, the intercept of the slope for the low effort target was lower in Study 3 than in the first two studies, and the intercept for the high effort target was higher. This difference in the intercepts across studies can be explained by the positive main effect of effort level in the present study (which included vignettes set in the verbal domain) as compared to the negative main effects of effort level in Studies 1-2 (which included vignettes set in the math domain).

Because of the difference in intercepts, we found that students with relatively strong taskelicited beliefs $(+1.5 S D)$ judged high effort targets to have more verbal ability than low effort targets (rather than perceiving effort to be inversely related to ability, as was the case in the math domain). In addition, students with relatively strong self-initiated beliefs in the verbal domain $(-1.5 S D)$ also judged high effort targets to have more ability than low effort targets, but did so to a greater extent than participants with task-elicited beliefs, as indicated by the significant interaction term. 
Finally, with respect to participants' ability mindsets, the effort source beliefs $\times$ effort level interaction remained significant when additional predictors were entered in the model (though it was only marginally significance $[p=.099]$ when excluding outliers [see Table S3]). The ability mindset $\times$ effort level interaction was not significant (but reached marginal significance when outliers were excluded).

\section{Discussion}

Study 3 revealed a positive main effect of effort level on judgments of verbal ability, such that participants' who scored at the mean or midpoint of the effort source measure judged students who expended high levels of effort to have higher levels of verbal ability than students who expended low levels of effort. The shift from a negative effect of effort level in a math context (i.e., particularly for participants at the midpoint of the other-oriented effort source measure in Studies 1 and 2) to a positive effect in an English writing context (Study 3) makes sense given that math assignments typically consist of close-ended problems, with students being rewarded for finding the one right answer as quickly as possible, while English writing assignments are typically more open-ended in nature, with students often being rewarded for elaborating their thoughts and demonstrating the depth of their knowledge.

Considering this difference in the main effects of effort level across domains, it is striking that we observed the same interaction involving effort source beliefs in the present study that we observed in Studies 1 and 2. Specifically, there was a significant effect of participants' effort source beliefs on their ability judgments for students who exhibited low levels of effort. That is, participants with task-elicited beliefs rated the ability of the low effort students higher than did participants with self-initiated beliefs. In contrast, there was a non-significant effect of effort source beliefs in the opposite direction for the high effort students in the verbal domain.

\section{General Discussion}


Prior research has shown that students are aware of both the positive and inverse relations between effort and ability (see Cimpian, 2017; Muenks \& Miele, 2017). As a result, motivation researchers have attempted to explain why some students are more inclined to think in terms of a positive relation, while other students tend to think in terms of an inverse relation. Understanding how students reason about the relation between effort and ability is important for predicting their motivation in educational contexts, as numerous studies have shown an association between participants' perceptions of competence and their desire or willingness to engage in academic tasks/courses (see Schunk \& DiBenedetto, 2016; Wigfield, Tonks, \& Klauda, 2016).

A number of studies have attempted to explain students' thinking about effort and ability in terms of what they generally believe about the nature of ability (i.e., in terms of their ability mindsets; e.g., Blackwell et al., 2007; Hong et al., 1999; Miele et al., 2013). An exception to this trend is a small number of studies that have examined students' thinking in terms of their perceptions of effort source (Muenks et al., 2016). However, because these studies involved temporarily framing an individual's effort as task-elicited or self-initiated, they could not address whether students have a tendency to perceive effort in a particular way in certain domains, or whether students spontaneously draw on this tendency when forming judgments of ability.

The present research extends existing work on perceived effort source by examining two primary questions. First, do college students have general beliefs about whether effort in a particular academic domain (e.g., math or English) tends to be task-elicited or self-initiated, and can these beliefs be reliably assessed? Second, in the absence of strong situational cues, do students' effort source beliefs influence how they think about the relation between levels effort and ability? In particular, do they spontaneously draw on these beliefs when evaluating the academic abilities of themselves and others? The findings of the present studies provide an affirmative response to both questions. That is, in the absence of experimental input (e.g., 
Muenks et al., 2016), we found natural and reliable differences in students' default effort source beliefs that predicted their judgments of their own (Study 2) and others students' (Study 1-3) academic abilities in both math (Studies 1 and 2) and English (Study 3) domains.

Furthermore, the pattern of association between students' effort source beliefs and their judgments of ability was generally the same across the three studies. That is, we consistently observed an effort source beliefs $\times$ effort level interaction, such that participants who tended to perceive effort as task-elicited generally rated the ability of students' who put forth low levels of effort on an academic task significantly higher than did participants who tended to perceive effort as self-initiated. In contrast, participants with more task-elicited beliefs tended to rate the ability of students who put forth high levels of effort lower than did participants with more selfinitiated beliefs (though this negative association between participants' effort source beliefs and ability judgments was only significant for self-judgments in Study 2). Finally, it is worth noting again that the design of our studies required participants to make their ability judgments before indicating their effort source beliefs, thereby ruling out the possibility that their judgments were based on externally primed effort source beliefs.

\section{Effort Source Beliefs and Self- versus Other-Oriented Ability Judgments}

In addition to these primary research questions, the present studies examined three other questions. The first of these questions pertains to whether or not students draw on effort source beliefs when forming judgments of their own ability, in addition to forming judgments of other students' abilities. Study 2 showed that, indeed, a self-oriented version of our effort source measure predicted participants' judgments of their own math ability in much the same way that the original other-oriented version of the measure predicted their judgments of others' math ability. One important difference was that, on average, participants reported stronger task-elicited beliefs for the self-oriented version of the measure than for the other-oriented version. A closer 
examination of the two measures revealed that this difference was primarily due to how participants responded to the self-initiated items for the vignettes in which they were asked to imagine themselves putting less effort into an assignment compared to another student.

Specifically, participants were reticent to say that the other student put in more effort because that student was more motivated than they were. In fact, the mean of the self-initiated items for these vignettes was significantly lower than for the same vignettes in the other-oriented version of the measure, $t(179)=7.07, p<.001$, Cohen's $d=.53$. A possible explanation is that the participants were exhibiting the kind of self-serving attributional bias that is well-documented in Western cultures (Mezulis, Abramson, Hyde, \& Hankin, 2004). That is, attributing their own low levels of effort to a lack of challenge more than a lack of motivation may serve to maintain a positive sense of self.

\section{Domain-Related Differences in Effort Source Beliefs and Ability Judgments}

An additional question that these studies addressed pertains to whether effort source beliefs are similarly predictive of students' ability judgments across different domains (e.g., math and English). Study 3 showed that the pattern of association between effort source beliefs and ability judgments was indeed similar in the English domain to what we found in the math domain (Studies 1 and 2). However, there were some important domain-related differences between studies. First, the mean of the other-focused effort source beliefs measure was significantly positive in Studies 1 and 2, with over 54\% of participants in each study having a positive score and less than $27 \%$ having a negative score. In contrast, the mean of the effort source measure was not significantly different from zero in Study 3, with only about 39\% of participants having a positive score and $46 \%$ having a negative score. These results suggest that participants tended to view the effort that students expend during math assignments as being elicited by the task, 
whereas they were no more likely to view the effort that students expend during English writing assignments as task-elicited than they were to view this effort as self-initiated.

This difference in the mean effort source beliefs across domains is consistent with attitudes and stereotypes in the U.S. regarding the difficulty of mathematics. Because it is commonly believed that "math is hard" (Ashcraft, 2002), students may come to perceive the effort that people expend during math activities as being directly elicited by the difficulty of the task. Considering that all of the other-oriented vignettes in our studies employed female names (in order to match the high proportion of females in our samples), this effect may also have been exacerbated by gender stereotypes that purport women to have less math ability than men (e.g., Cvencek, Meltzoff, \& Greenwald, 2011; Nosek, Banaji, \& Greenwald, 2002). That is, participants may have been particularly likely to view math-related effort as task-elicited because they viewed the women in the vignettes as likely to struggle in the math domain. In contrast, beliefs about English being a difficult subject or women having less verbal ability than men appear to be less commonplace. This may explain why the participants in Study 3 did not exhibit a general tendency to perceive effort during writing activities as being task-elicited.

Another important domain-related difference that emerged in our studies pertains to the main effect of effort level on participants' judgments of ability. In particular, participants who scored at the midpoint of the other-oriented, math-specific effort source scale in Studies 1 and 2 rated the math ability of students who expended relatively little effort to be higher than the math ability of students who expended a lot of effort (though this effect was only marginal in Study 1). However, in Study 3, the pattern was reversed: participants who scored at the mean or midpoint of the verbal-specific scale rated the verbal ability of the students who expended little effort to be substantially lower than the verbal ability of the students who expended a lot of effort. As suggested above, this difference may be due to students' distinct beliefs about the demands of 
math tasks versus writing assignments. Students are likely to view math tasks as consisting of close-ended problems that have one right answer. To the extent that they believe that the goal of such tasks is to produce the right answers as rapidly as possible (Lampert, 1990, p. 32), they may exhibit a general tendency to view people who complete math tasks quickly as being top performers and, in turn, view top performers as having high levels of math ability, regardless of their effort source beliefs. In contrast, students may believe that writing activities are open-ended in nature and are successfully completed by taking time to elaborate one's thoughts. If so, they may tend to view people who spend a lot of time completing writing activities as performing well and as, therefore, having high levels of verbal ability (regardless of what they perceive the source of this writing effort to be).

What we are proposing is that students may rely on two competing heuristics for interpreting effort level when evaluating people's abilities. One heuristic is based on participants' effort source beliefs and the other is based on beliefs about the relation of effort to performance for particular types of tasks. At times, these heuristics may work in opposite directions. Specifically, when someone expends low levels of effort on a writing activity, taskelicited beliefs may lead students to infer that the person has high levels of verbal ability (and did not need to work hard to be complete the task); whereas beliefs about open-ended tasks may lead the same students to infer that the person is unlikely to have performed well and, thus, has low levels of verbal ability. It is possible that students' final judgments regarding the verbal ability of the individual represent an average of these two competing inferences. Furthermore, in making these judgments, students may weigh inferences based on information about expected performance more strongly than inferences based on information about effort source. This latter possibility is consistent with the findings of Muenks et al. (2016). When participants in these studies were presented with vignettes that included explicit information about people's task 
performance, the participants used this information to form ability judgments and generally ignored information about effort source. It was only for the vignettes that excluded performance information that the authors observed substantial effects of the effort source manipulation.

The idea that participants combine inferences based on effort source beliefs with inferences based on domain-specific expectations about performance potentially explains why, in Study 3, participants with task-elicited beliefs viewed effort level as positively related to ability level, contrary to Studies 1 and 2. However, it is important to reiterate that they did so to a significantly lesser extent than participants with self-initiated beliefs. This was due to the fact that participants with task-elicited beliefs rated the ability of students' who put forth little effort significantly higher than did participants with self-initiated beliefs, which is generally consistent with prior theorizing about perceived effort source (Muenks et al., 2016; Muenks \& Miele, 2017).

\section{Relation of Effort Source Beliefs to Ability Mindsets}

A final question that the present studies addressed concerns the extent to which students' beliefs about the nature of effort (i.e., their effort source beliefs) and their beliefs about the nature of ability (i.e., their academic mindsets) independently predict students' ability judgments, as well as the extent to which these two beliefs are correlated with each other. When examining the effects of both beliefs simultaneously, we found that participants' effort source beliefs were generally a better predictor of their ability judgments than their academic mindsets. This suggests that in certain situations (e.g., when students are not yet aware of how they or their peers performed on a math task), effort source beliefs may be a stronger predictor of important motivational and behavioral outcomes associated with ability judgments. Future studies should directly examine the relation between our effort source beliefs measure and these outcomes. 
We also found that the two beliefs were, at best, weakly correlated with each other. Although we expected participants' effort source beliefs to be distinct from their ability mindsets, we were initially surprised by the lack of even a weak association in some of our studies. This surprise was due in part to the findings of a study by Heyman and Compton (2006; Study 3) that assessed kindergarteners' reasoning about ability. In particular, children who were primed to interpret another child's puzzle-solving efforts in terms of task difficulty (i.e., as having being task-elicited) were more likely than children who were not primed in this way to believe that some people can "never be really good at puzzles" (i.e., to endorse a fixed mindset). However, this study differed from the present study in some important ways. In particular, the participants in the study by Heyman and Compton were quite young and may have conceptualized intellectual ability differently from the college participants in the present study. In addition, children in the task-elicited condition were not compared to children who were primed with self-initiated effort source beliefs (instead they were compared to children exposed to a more neutral prime). It is possible that children primed with self-initiated beliefs would not have been as unlikely to endorse a fixed mindset as children in the neutral condition. Finally, the study by Heyman and Compton primed effort source beliefs (and only task-elicited beliefs) rather than measuring them. These differences may account for why Heyman and Compton observed an association between effort source and ability mindsets, while we did not.

Another difference between the study by Heyman and Compton and our studies that is worth noting pertains to the way in which ability mindsets were assessed. Heyman and Compton measured children's ability mindsets in a task-specific manner ("Are there some people who could never be really good at puzzles...?”), which matched the specificity of the effort primes. In contrast, we measured ability mindsets in a domain-general manner (e.g., "You can always substantially change how intelligent you are") that did not match the specificity of our primary 
effort source measure. Therefore, it is possible that measuring ability mindsets and effort source beliefs at the same level of specificity (i.e., both measures at a domain-general level or both at a domain-specific level) would have produced a stronger correlation between the two types of beliefs. However, we believe that this is unlikely for several reasons.

First, the general ability mindset measure was, at best, weakly correlated with a general measure of effort source beliefs that we report in the supplementary materials ( $r \mathrm{~s}=-.02$ to -.21$)$. If level of specificity matters, then the two domain-general measures should be more strongly correlated with each other. Second, as detailed in Footnote 4 and the supplementary materials, we had access to our participants' domain-specific ability mindsets, which we obtained as part of an unrelated set of studies. When we examined these domain-specific mindsets in relation to participants' domain-specific effort source beliefs, we found only weak correlations $(r s=-.20$ to -.31). This last finding, however, should be considered tentative because of the amount of time between when the two measures were administered (which could have produced smaller correlations) and because the domain-specific ability mindset measure (see Leslie, Cimpian, Meyer, \& Freeland, 2015) may have also assessed participants beliefs about effort (which could have produced larger correlations). Thus, future studies should administer a pure measure of participants' domain-specific ability mindsets at the same time as assessing participants' domainspecific effort source beliefs. Finally, as we argued in the Introduction, ability mindset and effort source beliefs are conceptually orthogonal; therefore, there are theoretical reasons for expecting the two constructs to be only weakly correlated.

\section{Implications, Limitations, and Future Directions}

In addressing these primary and secondary research questions, the present studies represent an important step in the investigation of perceived effort source as a motivational construct. Indeed, they establish for the first time that there exist natural and reliable differences 
in people's default effort source beliefs. Furthermore, they demonstrate that students spontaneously draw on these beliefs when evaluating the academic abilities of themselves and others in multiple academic domains. Finally, they demonstrate that effort source beliefs are orthogonal to their domain-general beliefs about the nature of ability (i.e., their ability mindsets), and that effort source beliefs are generally a better predictor of their ability judgments.

The present findings showing that effort source beliefs predict ability judgments, combined with prior findings showing that these judgments reliably predict academic motivation, suggest that effort source beliefs may account for important differences in students' motivation to engage in academic tasks. Thus, future research should directly examine the links from students' effort source beliefs to their academic motivation and achievement. If robust associations are observed, researchers should begin to examine whether students' effort source beliefs can be shaped through curricular interventions, in much the same way that they have examined the malleability of students' ability mindsets (Blackwell et al., 2007; Paunesku et al., 2015; Yeager et al., 2016). If effort source beliefs are found to operate through similar motivational mechanisms as ability mindsets, research examining these beliefs may turn out to have an important impact on educational practice (in much the same way that mindset research has becoming increasingly influential; e.g., Gates, 2015).

However, before these long-term aims are pursued, there are some limitations of the present studies that should be addressed. In particular, because our samples consisted of students at an elite American university, the average level of participants' effort source beliefs may have differed from the average for the general public. In particular, because these students are likely to experience high levels of academic motivation (and to observe their peers exhibit high levels of motivation), their effort source beliefs may be skewed toward the self-initiated side of the scale 
(relative to individuals who are less motivated to engage in academic tasks). In addition, they may be more likely to interpret self-initiated effort as indicating high levels of ability.

As with other elite American universities, the students at the school we recruited from tend to be Western, White, and well-off_-backgrounds associated with independent cultural norms (Markus \& Kitayama, 1991; Stephens, Markus, \& Phillips, 2014). As suggested above, these norms may have led the participants in our studies to exhibit self-serving biases when reporting self- versus other-oriented effort source beliefs and ability judgments (Mezulis et al., 2004). By contrast, students from cultures with interdependent cultural norms (e.g., Japan, more modest backgrounds) may be less likely to exhibit such biases. In addition, because the interdependent norms salient in Asian cultures are based on a shared Confucian heritage that deems diligence, persistence, and concentration as learning-related virtues (Heine, 2001; Li, 2004), it is possible that students in Asian cultures might be more likely than students in Western cultures to perceive effort as being self-initiated and to interpret such effort as a sign of high ability.

It is also worth noting again that the participants in our studies were predominately female. Considering that cultural biases may exist regarding the math ability of women versus men, future studies should include a higher proportion of males so that the effects of gender on students' effort source beliefs can be explored. Future studies should also aim to include samples that are more diverse in terms of age, ethnicity, and socioeconomic status, so that the current findings can be generalized more broadly.

Another limitation of the studies is the vignette-based materials that were used. Although the use of vignettes is common in this area of research (e.g., Hong et al., 1999; Jagacinski \& Nicholls, 1984, 1987; Muenks et al., 2016) and provides a high level of experimental control, it does not allow us to make strong claims about how students would interpret their actual 
experiences of effort or their real observations of another student working hard on a math task. Future studies should attempt to manipulate student' perceptions of mental effort during authentic academic activities and examine whether these perceptions interact with students' effort source beliefs in predicting their ability judgments.

A final limitation to consider is that the current studies investigated students' effort source beliefs regarding academic activities in only two domains: math and English. Considering that we found some interesting differences in the effects of these beliefs across domains, it is important that researchers expand the investigation of effort source to other academic areas (such as physics and music), as well as to non-academic areas (such as sports). Furthermore, it may be interesting to investigate whether the effects of effort source beliefs vary within a domain, depending on the nature of the tasks involved. For instance, we attributed the strong, positive main effect of effort source beliefs on ability judgments in the English domain to the open-ended nature of the writing tasks described in the vignettes. It may turn out that, for less open-ended English tasks (such as reading comprehension sections on standardized tests), we will observe less of a positive main effect or even a negative main effect (as with the math vignettes).

Another avenue for future research involves examining how effort source beliefs change over time, in both the near term (e.g., over the course of a semester) and the long term (e.g., over the course of development). Do effort source beliefs vary depending on the current academic context? For example, do some students hold more task-elicited beliefs later in the semester compared to the beginning of the semester? In addition, do very young children start off with a tendency to view effort as being self-initiated in most domains and then shift toward a more taskelicited interpretation of effort after repeated experiences of struggle in particular domains? It will also be important to explore whether one effort source belief is less adaptive than the other in particular academic contexts. For instance, are task-elicited beliefs less adaptive than self- 
initiated beliefs in math contexts because they make students reticent to work hard on challenging math task (for fear of being judged to have low ability)? In sum, the introduction of the novel effort source measure described in this paper provides numerous exciting opportunities for future research. 


\section{References}

Algina, J. (1982). Remarks on the analysis of covariance in repeated measures designs. Multivariate Behavioral Research, 17(1), 117-130.

Ashcraft, M. H. (2002). Math anxiety: Personal, educational, and cognitive consequences. Current directions in psychological science, 11(5), 181-185.

Blackwell, L. S., Trzesniewski, K. H., \& Dweck, C. S. (2007). Implicit theories of intelligence predict achievement across an adolescent transition: A longitudinal study and an intervention. Child Development, 78(1), 246-263. http://doi.org/10.1111/j.14678624.2007.00995.x

Blanton, H., Buunk, B. P., Gibbons, F. X., \& Kuyper, H. (1999). When better-than-others compare upward: Choice of comparison and comparative evaluation as independent predictors of academic performance. Journal of Personality and Social Psychology, $76(3), 420-430$.

Cimpian, A. (2017). Early reasoning about competence is not irrationally optimistic, nor does it stem from inadequate cognitive representations. In A. J. Elliot, C. S. Dweck \& D. S. Yeager (Eds.), Handbook of competence and motivation: Theory and application (2nd ed., pp. 387-407). New York, NY: Guilford Press

Cvencek, D., Meltzoff, A. N., \& Greenwald, A. G. (2011). Math-gender stereotypes in elementary school children. Child development, 82(3), 766-779.

Dunn, T. J., Baguley, T., \& Brunsden, V. (2014). From alpha to omega: A practical solution to the pervasive problem of internal consistency estimation. British Journal of Psychology, 105(3), 399-412. http://doi.org/10.1111/bjop.12046

Dweck, C. S. (1999). Self-theories: Their role in motivation, personality, and development. New York, NY: Psychology Press. 
Ericsson, K. A. (2006). The influence of experience and deliberate practice on the development of superior expert performance. In K. A. Ericsson, N. Charness, R. R. Hoffman, \& P. J. Feltovich (Eds.), The Cambridge handbook of expertise and expert performance (pp. 39 68). New York: Cambridge University Press.

Fisher, S. L., \& Ford, J. K. (1998). Differential effects of learner effort and goal orientation on two learning outcomes. Personnel Psychology, 51(2), 397-420.

Folmer, A. S., Cole, D. A., Sigal, A. B., Benbow, L. D., Satterwhite, L. F., Swygert, K. E., \& Ciesla, J. A. (2008). Age-related changes in children's understanding of effort and ability: Implications for attribution theory and motivation. Journal of Experimental Child Psychology, 99(2), 114-134.

Gates, B. (2015, December 7). What you believe affects what you achieve [Blog post]. Retrieved from https://www.gatesnotes.com/Books/Mindset-The-New-Psychology-of-Success

Gendolla, G. H., Wright, R. A., \& Richter, M. (2012). Effort intensity: Some insights from the cardiovascular system. In R. M. Ryan (Ed.), The Oxford handbook of human motivation (pp. 420-438). Oxford, UK: Oxford University Press.

Heider, F. (1958). The psychology of interpersonal relations. New York, NY: Wiley. http://dx.doi.org/10.1037/10628-000

Heine, S. J. (2001). Self as cultural product: An examination of East Asian and North American selves. Journal of personality, 69(6), 881-905.

Heyman, G. D., \& Compton, B. J. (2006). Context sensitivity in children's reasoning about ability across the elementary school years. Developmental Science, 9(6), 616-627.

Heyman, G. D., Gee, C. L., \& Giles, J. W. (2003). Preschool children's reasoning about ability. Child Development, 74(2), 516-534. 
Hong, Y., Chiu, C., Dweck, C. S., Lin, D. M.-S., \& Wan, W. (1999). Implicit theories, attributions, and coping: A meaning system approach. Journal of Personality and Social Psychology, 77(3), 588-599. http://doi.org/10.1037/0022-3514.77.3.588

Jagacinski, C. M., \& Nicholls, J. G. (1984). Conceptions of ability and related affects in task involvement and ego involvement. Journal of Educational Psychology, 76(5), 909-919.

Jagacinski, C. M., \& Nicholls, J. G. (1987). Competence and affect in task involvement and ego involvement: The impact of social comparison information. Journal of Educational Psychology, 79(2), 107-114.

Karabenick, J. D., \& Heller, K. A. (1976). A developmental study of effort and ability attributions. Developmental Psychology, 12(6), 559-560. http://doi.org/10.1037/00121649.12.6.559

Kelley, H. H. (1987). Causal schemata and the attribution process. In E. E. Jones, D. E. Kanouse, H. H. Kelley, R. E. Nisbett, S. Valins, \& B. Weiner (Eds.), Attribution: Perceiving the causes of behavior (pp. 151-174). Hillsdale, NJ, US: Lawrence Erlbaum Associates, Inc.

Koriat, A., Ackerman, R., Adiv, S., Lockl, K., \& Schneider, W. (2014). The effects of goaldriven and data-driven regulation on metacognitive monitoring during learning: A developmental perspective. Journal of Experimental Psychology: General, 143(1), 386.

Koriat, A., Ma'ayan, H., \& Nussinson, R. (2006). The intricate relationships between monitoring and control in metacognition: Lessons for the cause-and-effect relation between subjective experience and behavior. Journal of Experimental Psychology: General, 135(1), 36.

Lampert, M. (1990). When the problem is not the question and the solution is not the answer: Mathematical knowing and teaching. American Educational Research Journal, 27(1), 2963. 
Leslie, S. J., Cimpian, A., Meyer, M., \& Freeland, E. (2015). Expectations of brilliance underlie gender distributions across academic disciplines. Science, 347(6219), 262-265.

Li, J. (2004). Learning as a task or a virtue: US And Chinese preschoolers explain learning. Developmental Psychology, 40(4), 595-605.

Lou, N. M., \& Noels, K. A. (2016). Changing language mindsets: Implications for goal orientations and responses to failure in and outside the second language classroom. Contemporary Educational Psychology, 46, 22-33.

Markus, H. R., \& Kitayama, S. (1991). Culture and the self: Implications for cognition, emotion, and motivation. Psychological Review, 98(2), 224-253.

Marsh, H. W., Seaton, M., Trautwein, U., Lüdtke, O., Hau, K. T., O’Mara, A. J., \& Craven, R. G. (2008). The big-fish-little-pond-effect stands up to critical scrutiny: Implications for theory, methodology, and future research. Educational Psychology Review, 20(3), 319350.

McNeish, D. (in press). Thanks Coefficient Alpha, We'll Take It From Here. Psychological Methods. http://doi.org/10.1037/met0000144

Mezulis, A. H., Abramson, L. Y., Hyde, J. S., \& Hankin, B. L. (2004). Is there a universal positivity bias in attributions? A meta-analytic review of individual, developmental, and cultural differences in the self-serving attributional bias. Psychological Bulletin, 130(5), 711.

Miele, D. B., Son, L. K., \& Metcalfe, J. (2013). Children's naive theories of intelligence influence their metacognitive judgments. Child Development, 84(6), 1879-1886.

Molden, D. C., \& Winterheld, H. A. (2013). Motivations for promotion or prevention in close relationships. In J. A. Simpson \& L. Campbell (Eds.), The Oxford handbook of relationships (pp. 321-347). New York, NY: Oxford University Press. 
Muenks, K. (2016). The role of college students' perceptions of effort source on self-evaluations of academic ability (Doctoral dissertation, University of Maryland, College Park).

Muenks, K., \& Miele, D. B. (2017). Students' Thinking About Effort and Ability: The Role of Developmental, Contextual, and Individual Difference Factors. Review of Educational Research, 87(4), 707-735. http://doi.org/10.3102/0034654316689328

Muenks, K., Miele, D. B., Ramani, G. B., Stapleton, L. M., \& Rowe, M. L. (2015). Parental beliefs about the fixedness of ability. Journal of Applied Developmental Psychology, 41, 78-89.

Muenks, K., Miele, D. B., \& Wigfield, A. (2016). How students' perceptions of the source of effort influence their ability evaluations of other students. Journal of Educational Psychology, 108(3), 438-454. http://doi.org/10.1037/edu0000068

Nicholls, J. G., Patashnick, M., \& Mettetal, G. (1986). Conceptions of ability and intelligence. Child Development, 57(3), 636-645. http://doi.org/10.2307/1130342

Nosek, B. A., Banaji, M. R., \& Greenwald, A. G. (2002). Math = male, me = female, therefore math $\neq$ me. Journal of personality and social psychology, 83(1), 44-59.

Paunesku, D., Walton, G. M., Romero, C., Smith, E. N., Yeager, D. S., \& Dweck, C. S. (2015). Mind-set interventions are a scalable treatment for academic underachievement. Psychological science, 26(6), 784-793.

Saad, L. (2005). Math problematic for U.S. teens: More girls than boys find math, science toughest classes. Retrieved from https:/news.gallup.com/poll/16360/Math-Problematic-USTeens.aspx.

Schunk, D. H., \& DiBenedetto, M. K. (2016). Self-efficacy theory in education. In K. R. Wentzel \& D. B. Miele (Eds.), Handbook of motivation at school (2nd ed., pp. 34-54). New York: Routledge. 
Sheldon, K. M., Osin, E. N., Gordeeva, T. O., Suchkov, D. D., \& Sychev, O. A. (2017).

Evaluating the dimensionality of self-determination theory's relative autonomy continuum. Personality and Social Psychology Bulletin, 43(9), 1215-1238.

Stephens, N. M., Markus, H. R., \& Phillips, L. T. (2014). Social class culture cycles: How three gateway contexts shape selves and fuel inequality. Annual Review of Psychology, 65, 611-634.

Stewart, C. C., Wright, R. A., Azor Hui, S. K., \& Simmons, A. (2009). Outcome expectancy as a moderator of mental fatigue influence on cardiovascular response. Psychophysiology, 46(6), 1141-1149.

Thomas, M. S. C. (2009, June 10). A note on repeated measures ANCOVA. Retrieved May 6, 2011, from http://www.psyc.bbk.ac.uk/research/DNL/stats/Repeated Measures_ANCOVA.html

Thomas, M. S. C., Annaz, D., Ansari, D., Serif, G., Jarrold, C., \& Karmiloff-Smith, A. (2009). Using developmental trajectories to understand developmental disorders. Journal of Speech, Language, and Hearing Research, 52, 336-358. doi:10.1044/10924388(2009/07-0144

Wehrens, M. J., Kuyper, H., Dijkstra, P., Buunk, A. P., \& van der Werf, M. P. (2010). The longterm effect of social comparison on academic performance. European Journal of Social Psychology, 40(7), 1158-1171.

Wheeler, L., \& Suls, J. (2005). Social Comparison and Self-Evaluations of Competence. In A. J. Elliot \& C. S. Dweck (Eds.), Handbook of competence and motivation (pp. 566-578). New York, NY, US: Guilford Publications. 
Wigfield, A., Tonks, S. M., \& Klauda, S. L. (2016). Expectancy-value theory. In K. R. Wentzel \& D. B. Miele (Eds.), Handbook of motivation at school (2nd ed., pp. 55-74). New York: Routledge.

Wright, R. A. (2014). Presidential address 2013: Fatigue influence on effort—Considering implications for self-regulatory restraint. Motivation and Emotion, 38(2), 183-195.

Wright, R. A., Patrick, B. M., Thomas, C., \& Barreto, P. (2013). When fatigue promotes striving: Confirmation that success importance moderates resource depletion influence on effortrelated cardiovascular response. Biological Psychology, 93(2), 316-324.

Yang, Y., \& Green, S. B. (2011). Coefficient alpha: A reliability coefficient for the 21 st Century? Journal of Psychoeducational Assessment, 29(4), 377-392. http://doi.org/10.1177/0734282911406668

Yeager, D. S., Romero, C., Paunesku, D., Hulleman, C. S., Schneider, B., Hinojosa, C., ... \& Trott, J. (2016). Using design thinking to improve psychological interventions: The case of the growth mindset during the transition to high school. Journal of Educational Psychology, 108(3), 374. 
Table 1. Demographics of participants.

\begin{tabular}{lccc}
\hline & Study 1 & Study 2 & Study 3 \\
\hline$M_{\text {age }}(S D)$ & $18.83(.93)$ & $19.01(1.01)$ & $18.92(.98)$ \\
Gender & & & \\
Male & $17.3 \%$ & $12.8 \%$ & $17.9 \%$ \\
Female & $82.7 \%$ & $87.2 \%$ & $82.1 \%$ \\
Hispanic or Latino Heritage & $5.5 \%$ & $12.2 \%$ & $8.2 \%$ \\
Racial Background & & & \\
American Indian or Alaska Native & $.9 \%$ & $0 \%$ & $1.1 \%$ \\
Asian & $13.0 \%$ & $19.3 \%$ & $13.7 \%$ \\
Black or African-American & $2.8 \%$ & $5.7 \%$ & $5.5 \%$ \\
Native Hawaiian or Other Pacific Islander & $0 \%$ & $0 \%$ & $0 \%$ \\
White & $87.0 \%$ & $79.0 \%$ & $83.1 \%$ \\
\hline
\end{tabular}

Note: Latino heritage and racial background were solicited as part of separate questions, in line with NCES standards. Participants were asked to indicate all races that apply, thus percentages do not necessarily add up to $100 \%$. Latino heritage was not reported by 1 participant in Study 1 . Race was not reported by 2, 4, and 1 participant(s) in Studies 1-3, respectively. 
Table 2. Descriptive statistics for Studies 1-3.

\begin{tabular}{|c|c|c|c|c|}
\hline \multirow[b]{2}{*}{ Measure } & \multirow[b]{2}{*}{$M$} & \multirow[b]{2}{*}{$S D$} & \multicolumn{2}{|c|}{ Internal consistency ${ }^{\mathrm{a}}$} \\
\hline & & & $\omega_{T}(\alpha)$ & $r$ \\
\hline \multicolumn{5}{|l|}{ Study 1} \\
\hline Other-focused effort source beliefs (TE - SI) & .24 & .76 & -- & -- \\
\hline Task-elicited (TE) beliefs & 4.36 & .61 & $.85(.80)$ & -- \\
\hline Self-initiated (SI) beliefs & 4.12 & .69 & $.77(.74)$ & -- \\
\hline Ability mindsets & 3.87 & .88 & $.94(.93)$ & -- \\
\hline \multicolumn{5}{|l|}{ Judgments of ability } \\
\hline High-effort vignettes & 3.95 & .82 & -- & .66 \\
\hline Low-effort vignettes & 4.25 & .92 & -- & .52 \\
\hline \multicolumn{5}{|l|}{ Study 2} \\
\hline Other-focused effort source beliefs (TE - SI) & .38 & .83 & -- & -- \\
\hline Task-elicited (TE) beliefs & 4.44 & .63 & $.87(.82)$ & -- \\
\hline Self-initiated (SI) beliefs & 4.05 & .74 & $.82(.79)$ & -- \\
\hline Self-focused effort source beliefs (TE - SI) & .71 & .92 & & \\
\hline Task-elicited (TE) beliefs & 4.48 & .60 & $.82(.76)$ & -- \\
\hline Self-initiated (SI) beliefs & 3.77 & .76 & $.76(.73)$ & -- \\
\hline Ability mindsets & 3.74 & .93 & $.95(.94)$ & -- \\
\hline \multicolumn{5}{|l|}{ Other-focused judgments of ability } \\
\hline High-effort vignettes & 3.96 & .73 & -- & .66 \\
\hline Low-effort vignettes & 4.31 & .95 & -- & .61 \\
\hline \multicolumn{5}{|l|}{ Self-focused judgments of ability } \\
\hline High-effort vignettes & 3.88 & .78 & -- & .69 \\
\hline Low-effort vignettes & 4.23 & .97 & -- & .59 \\
\hline \multicolumn{5}{|l|}{ Study 3} \\
\hline Other-focused effort source beliefs (TE - SI) & -.08 & .73 & -- & -- \\
\hline Task-elicited (TE) beliefs & 4.16 & .66 & $.87(.83)$ & -- \\
\hline Self-initiated (SI) beliefs & 4.24 & .63 & $.75(.70)$ & -- \\
\hline Ability mindsets & 4.04 & .87 & $.94(.93)$ & -- \\
\hline \multicolumn{5}{|l|}{ Judgments of ability } \\
\hline High-effort vignettes & 4.46 & .81 & -- & .75 \\
\hline Low-effort vignettes & 3.57 & .89 & -- & .76 \\
\hline
\end{tabular}

${ }^{\text {a }}$ For measures with at least three items, we report omega total $\left(\omega_{T}\right)$ and Cronbach's alpha $(\alpha)$, which can be interpreted in a similar manner. Omega total (which we computed from polychoric correlations to account for the ordinal nature of the data) is recommended as a replacement for alpha because alpha makes rigid assumptions that can introduce considerable downward bias, especially when scales have a small number of items or are 
multidimensional (Dunn, Baguley, \& Brunsden, 2014; McNeish, in press; Yang \& Green, 2011). We include alpha here for the sake of comparison. For measures with only two items, we report the Pearson correlation $(r)$ between the items instead. We did not include coefficients for the overall effort source measure (TE - SI) because the TE and negatively-coded SI items did not positively load onto a single general factor. See the supplementary materials for more details. 
Table 3. Pattern matrix for the exploratory factor analysis of effort source belief items in Study 1. See the supplementary materials for a full description of the analysis and for the full text of the vignettes.

Vignette 1: How likely is it that Sarah worked harder because...?

TE 1: ...she found the assignment to be difficult, whereas Lisa found the assignment to be easy.

SI 1: ...she was motivated to perform well on the assignment, whereas Lisa was not motivated to perform well.

Vignette 2: How likely is it that Diane spent more time on the assignment because...?

TE 2: ...the assignment was very challenging for her, whereas the assignment was not particularly challenging for Rachel.

SI 2: ... she really enjoys working on math assignments, whereas Rachel does not enjoy math.

Vignette 3: How likely is it that Nancy spent more time on the assignment because...?

TE 3: ... she found the assignment to be very complicated, whereas Michelle found the assignment to be simple.

SI 3: ... she was really motivated to learn from the assignment, whereas Michelle did not care how much she learned.

Vignette 4: How likely is it that Jennifer expended more effort on the assignment because...?

TE 4: ...the assignment was very difficult for her, whereas it was fairly easy for Lindsey.

SI 4: ...she was very interested in the topic of the assignment, whereas Lindsey was not very interested in the topic.

Vignette 5: How likely is it that Dana put more effort into the assignment because...?

TE 5: ... she found that the assignment to be very demanding, whereas Stacey did not find the assignment to be demanding.

SI 5: ... she was motivated to do her best on the task, whereas Stacey did not care about doing

Vignette 6: How likely is it that Ellen, unlike Miriam, used the full time because...?

TE 6: ... she found the assignment to be very challenging, whereas Miriam did not find the assignment to be challenging.

SI 6: ... she was motivated to get a good grade on the assignment, whereas Miriam did not care about getting a good grade.

Note. Factor loadings $>|.3|$ appear in bold. TE $=$ task-elicited belief item. $\mathrm{SI}=$ Self-initiated belief item. 
Table 4. Results for repeated measures ANCOVAs predicting judgments of others' math ability from participants' effort source beliefs, the target student's effort level (low [coded as -1] versus high [coded as $+1]$ ), and the effort source $\times$ effort level interaction in Study 1. Participants' ability mindsets and the mindsets $\times$ effort level interaction were added as predictors in a second step.

\begin{tabular}{|c|c|c|c|c|c|c|c|c|}
\hline \multirow[b]{2}{*}{ Main effects and interactions } & \multicolumn{4}{|c|}{ Step 1} & \multicolumn{4}{|c|}{ Step 2} \\
\hline & $F$ & $d f$ & $p$ & $\eta^{2} p$ & $F$ & $d f$ & $p$ & $\eta_{p}^{2}$ \\
\hline Effort source beliefs & 2.48 & 1,108 & .118 & .022 & 2.26 & 1,107 & .136 & .021 \\
\hline Effort level & 5.88 & 1,108 & .017 & .052 & 5.90 & 1,107 & .017 & .052 \\
\hline Effort source beliefs $\times$ effort level & 7.30 & 1,108 & .008 & .063 & 6.97 & 1,107 & .010 & .061 \\
\hline Ability mindsets & - & - & - & - & 1.96 & 1,107 & .165 & .018 \\
\hline Ability mindsets $\times$ effort level & - & - & - & - & 1.23 & 1,107 & .270 & .011 \\
\hline Simple Effects & $t$ & $d f$ & $p$ & diff. & $t$ & $d f$ & $p$ & diff. \\
\hline \multicolumn{9}{|l|}{ Effects of effort level (high minus low) } \\
\hline For those with more self-initiated beliefs $(-1.5 S D)$ & .91 & 108 & .365 & .20 & .86 & 107 & .392 & .19 \\
\hline For those with more task-elicited beliefs $(+1.5 S D)$ & -3.59 & 108 & $<.001$ & -.79 & -3.54 & 107 & $<.001$ & -.78 \\
\hline \multicolumn{9}{|l|}{ Effects of effort source beliefs (+1.5 SD minus $-1.5 \mathrm{SD})$} \\
\hline For ratings of low effort targets & 3.07 & 213.02 & .002 & .75 & 2.97 & 210.88 & .003 & .73 \\
\hline For ratings of high effort targets & -.97 & 213.02 & .331 & -.24 & -.98 & 210.88 & .328 & -.24 \\
\hline
\end{tabular}

Note: The analyses above were conducted with outliers included. For analyses conducted with outliers excluded, see the supplementary materials. There were no differences in the significance of any effects (alpha level of .05) across these two sets of analyses. 
Table 5a. Results for repeated measures ANCOVAs predicting judgments of others' math ability from participants' other-focused effort source beliefs, the target's effort level (low [coded as -1] versus high [coded as +1$]$ ), and the effort source $\times$ effort level interaction in Study 2. Participants' ability mindsets and the mindsets $\times$ effort level interaction were added as predictors in a second step.

\begin{tabular}{|c|c|c|c|c|c|c|c|c|}
\hline \multirow[b]{2}{*}{ Main effects and interactions } & \multicolumn{4}{|c|}{ Step 1} & \multicolumn{4}{|c|}{ Step 2} \\
\hline & $F$ & $d f$ & $p$ & $\eta_{p}^{2}$ & $F$ & $d f$ & $p$ & $\eta_{p}^{2}$ \\
\hline Effort source beliefs & 3.84 & 1,178 & .052 & .021 & 4.25 & 1,177 & .041 & .023 \\
\hline Effort level & 12.40 & 1,178 & $<.001$ & .065 & 12.40 & 1,177 & $<.001$ & .065 \\
\hline Effort source beliefs $\times$ effort level & 10.32 & 1,178 & .002 & .055 & 9.39 & 1,177 & .003 & .050 \\
\hline Ability mindsets & - & - & - & - & .89 & 1,177 & .348 & .005 \\
\hline Ability mindsets $\times$ effort level & - & - & - & - & .95 & 1,177 & .331 & .005 \\
\hline Simple Effects & $t$ & $d f$ & $p$ & diff. & $t$ & $d f$ & $p$ & diff. \\
\hline \multicolumn{9}{|l|}{ Effects of effort level (high minus low) } \\
\hline For those with more self-initiated beliefs $(-1.5 S D)$ & .72 & 178 & .469 & .13 & .62 & 177 & .536 & .11 \\
\hline For those with more task-elicited beliefs $(+1.5 S D)$ & -4.62 & 178 & $<.001$ & -.82 & -4.50 & 177 & $<.001$ & -.81 \\
\hline \multicolumn{9}{|l|}{ Effects of effort source beliefs (+1.5 SD minus $-1.5 \mathrm{SD})$} \\
\hline For ratings of low effort targets & 3.74 & 332.76 & $<.001$ & .70 & 3.69 & 330.92 & $<.001$ & .69 \\
\hline For ratings of high effort targets & -1.37 & 332.76 & .173 & -.25 & -1.19 & 330.92 & .236 & -.22 \\
\hline
\end{tabular}

Note: The analyses above were conducted with outliers included. For analyses conducted with outliers excluded, see the supplementary materials. There were no differences in the significance of any effects (alpha level of .05) across these two sets of analyses. 
Table 5b. Results for repeated measures ANCOVAs predicting judgments of one's own math ability from participants' self-focused effort source beliefs, the target's effort level (low [coded as -1] versus high [coded as +1$]$ ), and the effort source $\times$ effort level interaction in Study 2. Participants' ability mindsets and the mindsets $\times$ effort level interaction were added as predictors in a second step.

\begin{tabular}{|c|c|c|c|c|c|c|c|c|}
\hline \multirow[b]{2}{*}{ Main effects and interactions } & \multicolumn{4}{|c|}{ Step 1} & \multicolumn{4}{|c|}{ Step 2} \\
\hline & $F$ & $d f$ & $p$ & $\eta^{2} p$ & $F$ & $d f$ & $p$ & $\eta^{2} p$ \\
\hline Effort source beliefs & .16 & 1,178 & .688 & $<.001$ & .12 & 1,177 & .732 & $<.001$ \\
\hline Effort level & 12.14 & 1,178 & $<.001$ & .064 & 12.14 & 1,177 & $<.001$ & .064 \\
\hline Effort source beliefs $\times$ effort level & 7.06 & 1,178 & .009 & .038 & 6.80 & 1,177 & .010 & .037 \\
\hline Ability mindsets & - & - & - & - & 1.58 & 1,177 & .210 & .009 \\
\hline Ability mindsets $\times$ effort level & - & - & - & - & .96 & 1,177 & .328 & .005 \\
\hline Simple Effects & $t$ & $d f$ & $p$ & diff. & $t$ & $d f$ & $p$ & diff. \\
\hline \multicolumn{9}{|l|}{ Effects of effort level (high minus low) } \\
\hline For those with more self-initiated beliefs $(-1.5 S D)$ & .28 & 178 & .778 & .05 & .24 & 177 & .807 & .05 \\
\hline For those with more task-elicited beliefs $(+1.5 S D)$ & -4.14 & 178 & $<.001$ & -.76 & -4.10 & 177 & $<.001$ & -.76 \\
\hline \multicolumn{9}{|l|}{ Effects of effort source beliefs (+1.5 SD minus $-1.5 \mathrm{SD})$} \\
\hline For ratings of low effort targets & 1.83 & 338.21 & $.068^{\mathrm{a}}$ & .36 & 1.83 & 336.07 & $.068^{\mathrm{a}}$ & .36 \\
\hline For ratings of high effort targets & -2.33 & 338.21 & .020 & -.46 & -2.26 & 336.07 & .025 & -.44 \\
\hline
\end{tabular}

Note: The analyses above were conducted with outliers included. For analyses conducted with outliers excluded, see the supplementary materials. ${ }^{a}$ Indicates effects that were not significant $(p>.10)$ in the analyses excluding outliers. 
Table 6. Results for repeated measures ANCOVAs predicting judgments of others' verbal ability from participants' effort source beliefs, the target student's effort level (low [coded as -1] versus high [coded as $+1]$ ), and the effort source $\times$ effort level interaction in Study 3. Participants' ability mindsets and the mindsets $\times$ effort level interaction were added as predictors in a second step.

\begin{tabular}{|c|c|c|c|c|c|c|c|c|}
\hline \multirow[b]{2}{*}{ Main effects and interactions } & \multicolumn{4}{|c|}{ Step 1} & \multicolumn{4}{|c|}{ Step 2} \\
\hline & $F$ & $d f$ & $p$ & $\eta_{p}^{2}$ & $F$ & $d f$ & $p$ & $\eta^{2} p$ \\
\hline Effort source beliefs & .67 & 1,182 & .414 & .004 & .65 & 1,181 & .422 & .004 \\
\hline Effort level & 95.89 & 1,182 & $<.001$ & .345 & 96.41 & 1,181 & $<.001$ & .348 \\
\hline Effort source beliefs $\times$ effort level & 6.22 & 1,182 & $.014^{\mathrm{b}}$ & .033 & 5.73 & 1,181 & $.018^{\mathrm{b}}$ & .031 \\
\hline Ability mindsets & - & - & - & - & .02 & 1,181 & .890 & $<.001$ \\
\hline Ability mindsets $\times$ effort level & - & - & - & - & 1.99 & 1,181 & $.160^{\mathrm{b}}$ & .011 \\
\hline Simple Effects & $t$ & $d f$ & $p$ & diff. & $t$ & $d f$ & $p$ & diff. \\
\hline \multicolumn{9}{|l|}{ Effects of effort level (high minus low) } \\
\hline For those with more self-initiated beliefs $(-1.5 S D)$ & 7.50 & 182 & $<.001$ & 1.24 & 7.42 & 181 & $<.001$ & 1.22 \\
\hline For those with more task-elicited beliefs $(+1.5 S D)$ & 3.34 & 182 & .001 & .55 & 3.43 & 181 & .001 & .57 \\
\hline \multicolumn{9}{|l|}{ Effects of effort source beliefs (+1.5 SD minus $-1.5 \mathrm{SD})$} \\
\hline For ratings of low effort targets & 2.38 & 362.24 & .018 & .45 & 2.30 & 360.51 & $.022^{\mathrm{b}}$ & .43 \\
\hline For ratings of high effort targets & -1.27 & 362.24 & .207 & -.24 & -1.20 & 360.51 & .233 & -.22 \\
\hline
\end{tabular}

Note: The analyses above were conducted with outliers included. For analyses conducted with outliers excluded, see the supplementary materials. ${ }^{b}$ Indicates effects that were marginally significant $(p<.10)$ in the analyses excluding outliers. 


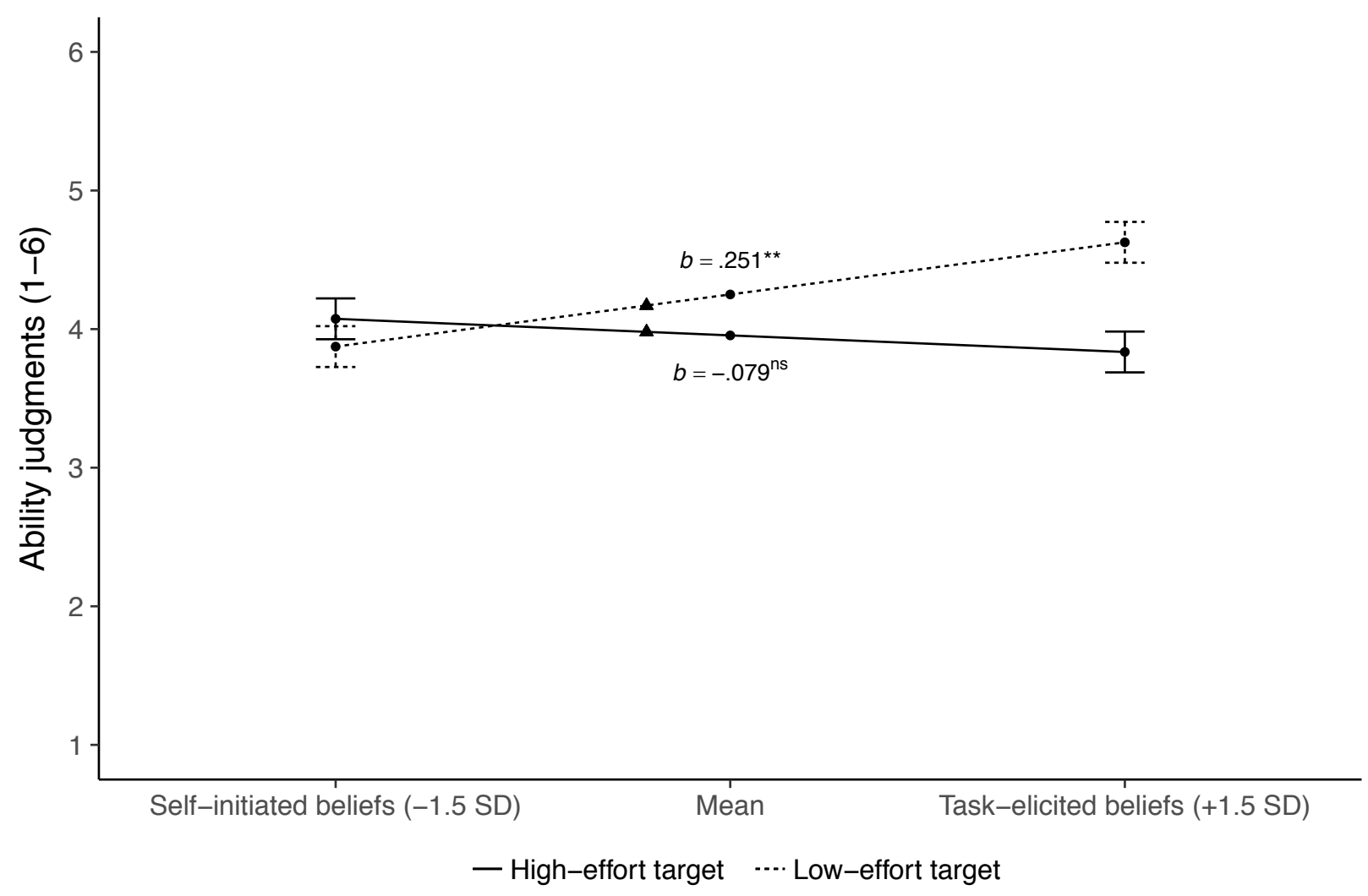

Figure 1. The relationship between participants' effort source beliefs and their judgments of math ability for high- and low-effort targets in Study 1.

Note: Mean ability judgments were estimated at 1.5 SD above and below the mean of the effort source beliefs measure (.24), based on the model reported in Table 4 (Step 1). $\Delta$ indicates mean ability judgment estimated at the midpoint of the effort source scale. Error bars represent $\pm 1 S E$ of the mean. Simple slope coefficients $(b)$ represent the increase in ability judgments corresponding to a $1 S D$ increase in effort source beliefs. ${ }^{* *} p<.01,{ }^{\text {ns }} p>.10$ 


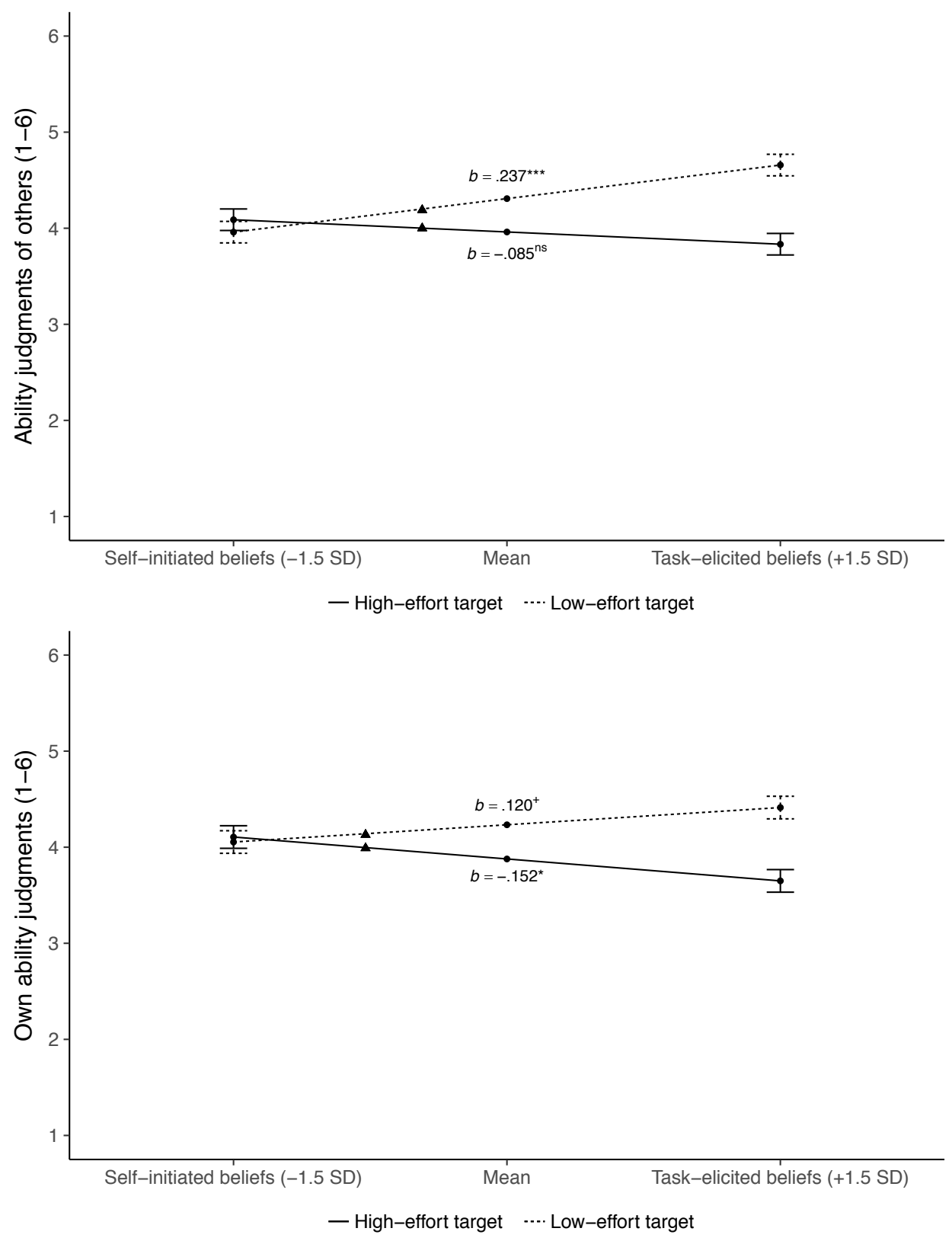

Figure 2. The relationship between participants' effort source beliefs and their judgments of (a) others' and (b) their own math ability when putting forth high or low effort in Study 2. Note: Mean ability judgments were estimated at 1.5 SD above and below the mean of the effort source beliefs measure (.38 for judgments of others, .71 for self-judgments), based on the models reported in Tables $5 \mathrm{a}$ and $5 \mathrm{~b}$ (Step 1). $\Delta$ indicates mean ability judgment estimated at the midpoint of the effort source scale. Error bars represent $\pm 1 S E$ of the mean. Simple slope coefficients $(b)$ represent the increase in ability judgments corresponding to a $1 S D$ increase in effort source beliefs. ${ }^{* * *} p<.001,{ }^{*} p<.05,{ }^{\dagger} p<.10,{ }^{\text {ns }} p>.10$ 


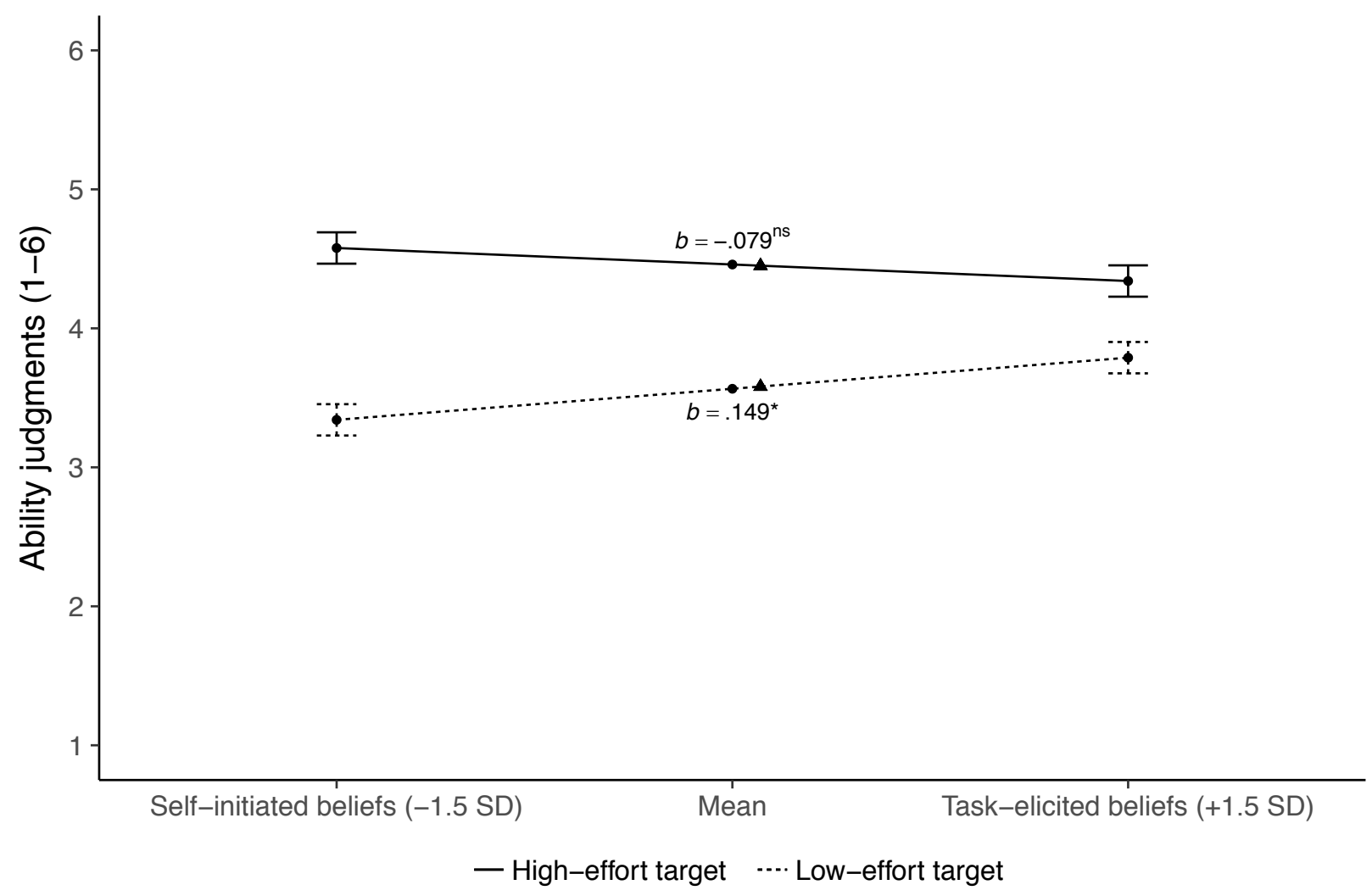

Figure 3. The relationship between participants' effort source beliefs and their judgments of verbal ability for high- and low-effort targets in Study 3.

Note: Mean ability judgments were estimated at 1.5 SD above and below the mean of the effort source beliefs measure (.08), based on the model reported in Table 6 (Step 1). $\Delta$ indicates mean ability judgment estimated at the midpoint of the effort source scale. Error bars represent $\pm 1 S E$ of the mean. Simple slope coefficients $(b)$ represent the increase in ability judgments corresponding to a $1 S D$ increase in effort source beliefs. ${ }^{*} p<.05,{ }^{\text {ns }} p>.10$ 


\section{Appendix}

\section{Other-Focused Ability Judgment Vignettes}

The following vignettes were set in a math problem solving context in Studies 1-2, and in an English writing context in Study 3:

1. Jennifer, a college student, is sitting in her Calculus [English Literature] class when the professor gives the class a set of problems [writing assignment] to work on individually. The class is given 15 minutes to complete the assignment, and Jennifer spends the full 15 minutes on the problems, concentrating hard, and putting in a lot of effort. Based on the information above, how would you evaluate Jennifer's math ability? (high-effort vignette)

2. Amy, a college student, is sitting in her Linear Algebra [English Composition] class when the professor gives the class a set of problems [writing assignment] to work on individually. The class is given 18 minutes to complete the assignment, and Amy spends the full 18 minutes on the problems, concentrating hard, and putting in a lot of effort. Based on the information above, how would you evaluate Amy's math ability? (high-effort vignette)

3. Cassidy, a college student, is sitting in her Calculus [English Literature] class when the professor gives the class a set of problems [writing assignment] to work on individually. The class is given 15 minutes to complete the assignment, and Cassidy spends only 10 minutes on the problems, putting forth relatively little effort. Based on the information above, how would you evaluate Cassidy's math ability? (low-effort vignette)

4. Rebecca, a college student, is sitting in her Linear Algebra [English Composition] class when the professor gives the class a set of problems [writing assignment] to work on individually. The class is given 18 minutes to complete the assignment, and Rebecca spends only 12 minutes on the problems, putting forth relatively little effort. Based on the information above, how would you evaluate Rebecca's math ability? (low-effort vignette)

\section{Self-Focused Ability Judgment Vignettes}

In Study 2, participants also completed the following four self-focused vignettes:

1. Imagine that you are sitting in a Calculus class that you enrolled in when the professor gives the class a set of problems to work on individually. The class is given 15 minutes to complete the assignment, and you spend the full 15 minutes on the assignment, concentrating hard, and putting in a lot of effort. Based on the information above, how would you evaluate your own math ability? (high-effort vignette)

2. Imagine that you are sitting in a Linear Algebra class that you enrolled in when the professor gives the class a set of problems to work on individually. The class is given 18 minutes to complete the assignment, and you spend the full 18 minutes on the assignment, concentrating hard, and putting in a lot of effort. Based on the information above, how would you evaluate your own math ability? (high-effort vignette) 
3. Imagine that you are sitting in a Calculus class that you enrolled in when the professor gives the class a set of problems to work on individually. The class is given 15 minutes to complete the assignment, and you spend only 10 minutes on the assignment, putting forth relatively little effort. Based on the information above, how would you evaluate your own math ability? (low-effort vignette)

4. Imagine that you are sitting in a Linear Algebra class that you enrolled in when the professor gives the class a set of problems to work on individually. The class is given 18 minutes to complete the assignment, and you spend only 12 minutes on the assignment, putting forth relatively little effort. Based on the information above, how would you evaluate own your math ability? (low-effort vignette)

\section{Other-Focused Effort Source Beliefs Measure}

The items below were set in a math context in Studies 1-2, and in an English context in Study 3:

1. Two college students, Sarah and Lisa, are sitting in a Math [an English] class. The professor gives the class an assignment to work on individually. Sarah works hard on the assignment, while Lisa does not work very hard. How likely is it that Sarah worked harder because...?

a. ...she found the assignment to be difficult, whereas Lisa found the assignment to be easy. (task-elicited beliefs)

b. ...she was motivated to perform well on the assignment, whereas Lisa was not motivated to perform well. (self-initiated beliefs)

2. Two college students, Diane and Rachel, are sitting in a Math [an English] class. The professor gives the class an assignment to work on individually. Diane finishes the assignment in 15 minutes, while Rachel finishes in 10 minutes. How likely is it that Diane spent more time on the assignment because...?

a. ...the assignment was very challenging for her, whereas the assignment was not particularly challenging for Rachel. (task-elicited beliefs)

b. ...she really enjoys working on math [English] assignments, whereas Rachel does not enjoy math [English]. (self-initiated beliefs)

3. Two college students, Nancy and Michelle, are sitting in a Math [an English] class. The professor gives the class an assignment to work on individually. Nancy works on the assignment for the entire class period, while Michelle finishes the assignment ten minutes before the end of class. How likely is it that Nancy spent more time on the assignment because...?

a. ...she found the assignment to be very complicated, whereas Michelle found the assignment to be simple. (task-elicited beliefs)

b. ...she was really motivated to learn from the assignment, whereas Michelle did not care how much she learned. (self-initiated beliefs) 
4. Two college students, Jennifer and Lindsey, are sitting in a Math [an English] class. The professor gives the class an assignment to work on individually. Jennifer expends a good deal of effort on the assignment, whereas Lindsey did not expend much effort. How likely is it that Jennifer expended more effort on the assignment because...?

a. ...the assignment was very difficult for her, whereas it was fairly easy for Lindsey. (task-elicited beliefs)

b. ...she was very interested in the topic of the assignment, whereas Lindsey was not very interested in the topic. (self-initiated beliefs)

5. Two college students, Dana and Stacey, are sitting in a Math [an English] class. The professor gives the class an assignment to work on individually. Dana puts a lot of effort into the assignment, while Stacey does not put in a lot of effort. How likely is it that Dana put more effort into the assignment because...?

a. ...she found that the assignment to be very demanding, whereas Stacey did not find the assignment to be demanding. (task-elicited beliefs)

b. ...she was motivated to do her best on the task, whereas Stacey did not care about doing her best. (self-initiated beliefs)

6. Two college students, Ellen and Miriam, are sitting in a Math [an English] class. The professor gives the class an assignment to work on individually. Ellen is very focused on the assignment for the entire 20 minutes, whereas Miriam finishes well before the time is up. How likely is it that Ellen, unlike Miriam, used the full time because...?

a. ...she found the assignment to be very challenging, whereas Miriam did not find the assignment to be challenging. (task-elicited beliefs)

b. ...she was motivated to get a good grade on the assignment, whereas Miriam did not care about getting a good grade. (self-initiated beliefs)

\section{Self-Focused Effort Source Beliefs Measure}

In Study 2, participants also completed the following self-focused version of the effort source beliefs measure:

1. You and another student, Lisa, are sitting in a Math class. The professor gives the class an assignment to work on individually. You work hard on the assignment, while Lisa does not work very hard. How likely is it that you worked harder because...?

a. ...you found the assignment to be difficult, whereas Lisa found the assignment to be easy. (task-elicited beliefs)

b. ...you were motivated to perform well on the assignment, whereas Lisa was not motivated to perform well. (self-initiated beliefs)

2. You and another student, Rachel, are sitting in a Math class. The professor gives the class an assignment to work on individually. You finish the assignment in 15 minutes, while Rachel 
finishes in 10 minutes. How likely is it that you spent more time on the assignment because...?

a. ...the assignment was very challenging for you, whereas the assignment was not particularly challenging for Rachel. (task-elicited beliefs)

b. ...you really enjoy working on Math assignments, whereas Rachel does not enjoy Math. (self-initiated beliefs)

3. You and another student, Michelle, are sitting in a Math class. The professor gives the class an assignment to work on individually. You work on the assignment for the entire class period, while Michelle finishes the assignment ten minutes before the end of class. How likely is it that you spent more time on the assignment because...?
a. ...you found the assignment to be very complicated, whereas Michelle found the assignment to be simple. (task-elicited beliefs)
b. ...you were really motivated to learn from the assignment, whereas Michelle did not care how much she learned. (self-initiated beliefs)

4. You and another student, Jennifer, are sitting in a Math class. The professor gives the class an assignment to work on individually. Jennifer expends a good deal of effort on the assignment, whereas you do not expend much effort. How likely is it that Jennifer expended more effort on the assignment because...?
a. ...the assignment was very difficult for her, whereas it was fairly easy for you. (task- elicited beliefs)
b. ...she was very interested in the topic of the assignment, whereas you were not very interested in the topic. (self-initiated beliefs)

5. You and another student, Dana, are sitting in a Math class. The professor gives the class an assignment to work on individually. Dana puts a lot of effort into the assignment, while you do not put in a lot of effort. How likely is it that Dana put more effort into the assignment because...?
a. ...she found the assignment to be very demanding, whereas you did not find the assignment to be demanding. (task-elicited beliefs)
b. ...she was motivated to do her best on the assignment, whereas you did not care about doing your best. (self-initiated beliefs)

6. You and another student, Ellen, are sitting in a Math class. The professor gives the class 20 minutes to work on an assignment individually. Ellen is very focused on the assignment for the entire 20 minutes, whereas you finish well before the time is up. How likely is it that Ellen, unlike you, used the full time because...?
a. ...she found the assignment to be very challenging, whereas you did not find the assignment to be challenging. (task-elicited beliefs)
b. ...she was motivated to get a good grade on the assignment, whereas you did not care about getting a good grade. (self-initiated beliefs)

